\title{
Factor-Analysis-Based Directional Distance Function: The case of New Zealand hospitals
}

Zhongqi Deng $^{\mathrm{a}}$ Nan Jiang ${ }^{\mathrm{b}}$ Ruizhi Pang ${ }^{\mathrm{c}}$

${ }^{\text {a }}$ School of Economics, Sichuan University, China.

${ }^{\mathrm{b}}$ School of Economics, Auckland University of Technology, New Zealand.

${ }^{\mathrm{c}}$ College of Economic and Social Development, Nankai University, China.

\section{Abstract}

This paper develops a new factor-analysis-based (FAB) approach for choosing the optimal direction in a directional distance function (DDF) analysis. It has the combined merits of factor analysis and slacks-based measure (SBM) and incorporates the relative ease with which various input-output could be adjusted. This development relieves the dependency of price information that is normally unavailable in the provision of public goods. This new FAB-DDF model has been applied on a dataset containing all public hospitals in New Zealand (NZ) observed during 2011-2017. The empirical results indicate that the average reduction across different labor is in the range of 3-10 percent, and the corresponding figure for capital input is 25.7 percent. The case-adjusted inpatient-discharge and price-adjusted outpatient-visit are used as measures of desirable output, the average efficiencies are 92.7 percent and 99 percent respectively. Hospital readmission within 28 days of discharge is used as a measure for undesirable output, and the average efficiency score is 90 percent. These evidence support the suspicion that perverse incentives might exist under the National Health Targets abolished in 2018, which was a set of six indicators used in the last decade to evaluate the performance of local District Health Boards.

Keywords: factor-analysis-based measure; directional distance function; NZ hospital efficiency; hospital readmission

JEL classification: C61; D24; I11; I18 


\section{Introduction}

As the outcome of the integration between distance function and gauge function, the directional distance function (DDF) analysis has gathered considerable momentum in production economics with empirical applications in a wide range of areas such as health, labor, energy and transport etc. Built upon the exploration work established by many studies (Farrell, 1957; Shephard, 1970; Shephard and Färe, 1974; McFadden, 1978; Färe, 1988; and Luenberger, 1992, 1994, 1995), the first DDF was proposed by Chambers et al. (1996), and the analysis was further developed in Chung et al. (1997) and Chambers et al. (1998). Discussions about the theoretical properties of a DDF are available in these works as well as the modelling of bad (undesirable) outputs. However, little advancement has been made toward the choice of directions. A large number of applications arbitrarily set a fixed direction, which is either exclusively towards the reduction of bad output(s), or allowing for radical contraction in inputs at the same time. When it has been demonstrated that efficiency estimates may not be robust to the choice of directions in such analysis (Vardanyan and Noh, 2006; Agee et al. 2012; Pang and Deng, 2014), the issue of how to select the optimal direction emerged. For example, Pang and Deng (2014) find that the average efficiency of Chinese service sectors is above that of the industrial sectors if only reductions in sulfur dioxide and carbon dioxide emissions were considered. The conclusion would be reversed when labor, capital and energy inputs are allowed to be simultaneously contracted.

Alternative directions were suggested previously (Färe et al. 2005; Färe et al. 2006; Kumar, 2006; Lee et al. 2002 etc.), but none of these studies treats direction as an endogenous choice variable until recently (Färe et al. 2013; Zofio et al. 2013; and Atkinson and Tsionas, 2016; Petersen, 2018). The idea is to find the optimal direction towards profit maximization through the construction of a profit function. The optimal choice in the direction of marginal profit maximization is further suggested by Lee 
(2014) and Deng (2016). ${ }^{1}$ Nonetheless, applications of the above techniques require data on prices. Given the difficulty of obtaining accurate information on price, especially the price of undesirable output, these developments are mainly theoretical with limited empirical attention. In addition, another constantly neglected aspect in performance studies is the ease at which inputs and outputs can be adjusted. To illustrate, for those inputs (or bad outputs) which can be easily reduced, the redundancy of these variables can happen immediately and therefore pose a lesser concern; on the contrary, for those that are more onerous to adjust, once committed, efficiency can only be improved in the long run and should be given more consideration in designing policies initiatives encouraging more efficient utilization of public resources. The new factor-analysis-based DDF model proposed in this study addresses this issue and the application does not require data on prices.

We first demonstrate that the selection of an optimal direction vector in a DDF analysis is equivalent to the choice of an optimal weight vector in a slacks-based measure (SBM) of efficiency. Next, we prove that the optimal weight vector in an SBM can be found using a factor-analysis-based approach. ${ }^{2}$ Although both parametric method (Färe et al. 2005, 2006, 2012; Chambers et al. 2013; Feng and Serletis, 2014; Atkinson and Tsionas, 2016; Badau et al. 2016) and nonparametric method (Chung et al. 1997; Boyd et al. 2002; Zofio et al. 2013; Lee, 2014; Pang et al. 2015; Deng, 2016; Petersen, 2018) are available to construct a DDF, this study focuses solely on the nonparametric technique.

In terms of empirical application, a newly available multifaceted administrative dataset is employed. This dataset contains all public hospitals managed by the 20 local District Health Boards (DHBs) in New Zealand (NZ) during the period of 2011-

\footnotetext{
${ }^{1}$ Maximizing the marginal profit is considered to be a more practical approach compared to the conventional profit maximization because it involves a step-by-step improvement and "wait-and-see" decision process.

2 For the principle of factor analysis method, refer to Boivin and $\mathrm{Ng}$ (2006), Foerster et al. (2011) and Johnson and Wichern (2013).
} 
2017..$^{3}$ The majority of health care systems worldwide face challenges imposed by tight public budgets, an aging population, and more chronic diseases. In 2017, total health expenditures in NZ amounts to $\$ 24.5$ billion and 9.2\% of GDP (OECD Health Statistics). Debates about system inefficiency resulted in a series of major structural changes since the 1990s (Ashton, 2005, 2009; Cumming et al. 2014 and Mays et al. 2013). In spite of this, sound performance measures are yet to be established for the health sector.

Healthcare services in NZ is mainly funded through tax. Public hospitals provide most of the secondary and tertiary healthcare services such as surgery, specialist treatments and emergency services. General practitioners, practice nurses, pharmacists and other health professionals working within a Primary Health Organization (PHO) are contracted by the government to provide primary healthcare services. District Health Boards (DHBs) were the local authorities responsible for providing health services to their geographically defined communities. DHBs own public hospitals as their provider arms and are funded by the Ministry of Health (MOH) through a populationbased funding formula (PBFF). ${ }^{4}$ A key objective for $\mathrm{MOH}$ is to ensure that providers exert a sufficient amount of effort. However, providers' effort is usually unobservable to $\mathrm{MOH}$ and thus impossible to contract on directly. $\mathrm{MOH}$ can instead use payment schemes that affect providers' willingness to exert effort. A popular approach is to pay providers for their performance on measurable process and outcome indicators (Eggleston, 2005; Oxholm et al. 2018). In NZ performance of the DHBs were monitored through quarterly assessment of the six indicators specified by the National Health Targets. ${ }^{5}$ These targets are primarily partial output measures and there is no

\footnotetext{
${ }^{3}$ Initially, there were 21 DHBs established in 2000, two of them were merged in 2010. The analysis in this study is built upon the stabilized post-merge period from 2011 to 2017. Profiles of the 20 DHBs are presented in Appendix 1. They vary considerably in size, with Waitemata being the largest DHB serving over half a million population and West Coast being the smallest DHB with a population just over 30,000.

4 The PBFF allocates resources between DHBs based on a core model which assesses the relative healthcare needs of the local populations via historical average expenditure for different demographic groups. The PBFF does incorporate adjusters to account for factors such as populations with low access to healthcare services, rural areas and overseas visitors and refugees.

5 The National Health Targets are presented in Appendix 2, they were first introduced in 2008 aiming to improve the performance of the health sector.
} 
control for input usage. Many dimensions of healthcare services, such as acute hospital admissions and non-Emergency Department outpatient-visit, are completely unaccounted for. The degree to which the targets could create perverse incentives by diverting resources away from unmeasured services to measured ones were unknown. In other words, there were risks that the National Health Targets were achieved at the expenses of lowering overall productivity and efficiency. Many concern that the hospitals might, for instance, discharge acute patients sooner in order to accommodate more elective surgeries, leading to undesirable outcomes. This study employs the number of readmissions within 28 days of discharge as a measure of undesirable (bad) output.

The rest of the paper proceeds as follows. The next section discusses the dual correspondence between the directional distance function (DDF) and slacks-based measure (SBM) of efficiency. Section 3 develops the new FAB-DDF model and provides a step-by-step guide for application. The next section evaluates the efficiency of NZ public hospitals using this new approach and compares the results with those obtained under conventional DDFs and SBM. Section 5 concludes.

\section{Dualities}

\subsection{The directional distance functions}

Let $\boldsymbol{x}=\left(x_{1}, \cdots, x_{N}\right) \in \mathfrak{R}_{+}^{N}$ denotes the vector for inputs, $\boldsymbol{y}=\left(y_{1}, \cdots, y_{M}\right) \in \mathfrak{R}_{+}^{M}$ denotes a vector of desirable (good) outputs and $\boldsymbol{b}=\left(b_{1}, \cdots, b_{B}\right) \in \mathfrak{R}_{+}^{B}$ denotes a vector of undesirable (bad) outputs. The production possibility set which represents the technology describing the transformation of inputs into outputs is given by:

$\mathbb{T}^{\mathrm{DDF}}=\{(\boldsymbol{x}, \boldsymbol{y}, \boldsymbol{b}):$ such that $\boldsymbol{x}$ can produce $(\boldsymbol{y}, \boldsymbol{b})\}$

One can refer to Chambers et al. (1996), Chung et al. (1997), and Färe et al. (2006) for the standard assumptions made on the technology. ${ }^{6}$ A DDF is an alternative way

${ }^{6}$ Standard assumptions include: it is a convex, closed set; doing nothing is feasible; there is no free lunch; inputs 
to represent the technology from a computational viewpoint and can be described as:

$\vec{D}(\boldsymbol{z} ; \boldsymbol{g})=\max \left\{\beta:(\boldsymbol{z}+\beta \boldsymbol{g})^{\prime}=\left(\boldsymbol{x}+\beta \boldsymbol{g}_{\boldsymbol{x}}, \boldsymbol{y}+\beta \boldsymbol{g}_{\boldsymbol{y}}, \boldsymbol{b}+\beta \boldsymbol{g}_{\boldsymbol{b}}\right) \in \mathbb{T}^{\mathrm{DDF}}\right\}$

Here, $\boldsymbol{z}=(\boldsymbol{x}, \boldsymbol{y}, \boldsymbol{b})^{\prime}$ is the collective vector in $\mathfrak{R}_{+}^{N} \times \mathfrak{R}_{+}^{M} \times \mathfrak{R}_{+}^{B}$ containing all observed inputs and outputs. $\boldsymbol{g}=\left(\boldsymbol{g}_{x}, \boldsymbol{g}_{\boldsymbol{y}}, \boldsymbol{g}_{\boldsymbol{b}}\right)^{\prime}$ is the vector of "directions" in which the observed inputs and outputs could be scaled. It is natural to specify that $\boldsymbol{g}_{\boldsymbol{x}}<\mathbf{0}$, $\boldsymbol{g}_{\boldsymbol{y}}>\mathbf{0}$ and $\boldsymbol{g}_{\boldsymbol{b}}<\mathbf{0}$. Thus, this function seeks the simultaneous maximum proportional reduction in $(\boldsymbol{x}, \boldsymbol{b})$ and expansion in $\boldsymbol{y}$. The distance is conventionally measured in a preassigned fixed direction to the boundary of $\mathbb{T}^{\mathbf{D D F}}$, for example, arbitrarily setting $\boldsymbol{g}=(-\boldsymbol{x}, \boldsymbol{y},-\boldsymbol{b})^{\prime}$. Common properties of the DDF include:

P1: Translation: $\vec{D}(\mathbf{z}+\tau \boldsymbol{g} ; \boldsymbol{g})=\vec{D}(\boldsymbol{z} ; \boldsymbol{g})-\tau$.

P2: Homogeneity of degree minus one in $\boldsymbol{g}: \vec{D}(\mathbf{z} ; \tau \boldsymbol{g})=\tau^{-1} \vec{D}(\mathbf{z} ; \boldsymbol{g})$.

P3: Input monotonicity: $\vec{D}(\widetilde{\boldsymbol{x}}, \boldsymbol{y}, \boldsymbol{b} ; \boldsymbol{g}) \geq \vec{D}(\boldsymbol{x}, \boldsymbol{y}, \boldsymbol{b} ; \boldsymbol{g})$ for $\breve{\boldsymbol{x}} \geq \boldsymbol{x}$.

P4: Good output monotonicity: $\vec{D}(\boldsymbol{x}, \breve{\boldsymbol{y}}, \boldsymbol{b} ; \boldsymbol{g}) \leq \vec{D}(\boldsymbol{x}, \boldsymbol{y}, \boldsymbol{b} ; \boldsymbol{g})$ for $\breve{\boldsymbol{y}} \geq \boldsymbol{y}$.

P5: Bad output monotonicity: $\vec{D}(\boldsymbol{x}, \boldsymbol{y}, \breve{\boldsymbol{b}} ; \boldsymbol{g}) \geq \vec{D}(\boldsymbol{x}, \boldsymbol{y}, \boldsymbol{b} ; \boldsymbol{g})$ for $\breve{\boldsymbol{b}} \geq \boldsymbol{b}$.

P6: Concavity: $\vec{D}(\boldsymbol{z} ; \boldsymbol{g})$ is concave in $\boldsymbol{z}+\beta \boldsymbol{g} \in \mathbb{T}^{\mathrm{DDF}}$.

P7: Non-negativity: $\vec{D}(z ; g) \geq 0$ if and only if $\boldsymbol{z}+\beta \boldsymbol{g} \in \mathbb{T}^{\mathbf{D D F}}$.

Property P1 states that if inputs and bad outputs are contracted by $\tau\left(\left|\boldsymbol{g}_{x}\right|,\left|\boldsymbol{g}_{\boldsymbol{b}}\right|\right)^{7}$ and good outputs are expanded by $\tau \boldsymbol{g}_{\boldsymbol{y}}$, then the value of the resulting distance function will be more efficient by the amount $\tau$. Property $\mathrm{P} 2$ is the analog of $\mathrm{P} 1$, stating that changing the unit of direction vector does not change the relative size of inefficiency. Property P3 is a monotonicity property corresponding to strong disposability of inputs. It states that if a firm produces the same amount of desirable and undesirable outputs, but with more inputs, inefficiency will not decrease. Similarly, property P4 states that if desirable output increase, holding inputs and undesirable outputs constant, inefficiency does not increase. Property P5 is monotonicity with respect to bad output, increase in bad output will lead to non-decreasing inefficiency, holding

and good outputs are freely disposable; good and bad outputs are null-joint and weakly disposable etc.

${ }^{7}$ Here, $|\cdot|$ is to obtain the absolute values for all elements of a vector. 
inputs and desirable outputs constant. Property P6 is proven in Luenberger (1992) and is equivalent to assume the production possibility set $\mathbb{T}^{\mathbf{D D F}}$ is convex. Property P7 specifies that inefficiency is non-negative, zero inefficiency exists if and only if the observation is operating on the boundary of $\mathbb{T}^{\mathrm{DDF}}$, i.e. $100 \%$ efficient.

\subsection{The slacks-based measure of efficiency}

The production possibility set in a SBM of efficiency can be defined in a similar way as the following:

$\mathbb{T}^{\mathbf{S B M}}=\{(\boldsymbol{x}, \boldsymbol{y}, \boldsymbol{b}):$ such that $\boldsymbol{x}$ can produce $(\boldsymbol{y}, \boldsymbol{b})\}$

One can refer to Tone (2001) and Fukuyama and Weber (2009) for the standard assumptions made on the technology. A slacks-based measure of efficiency can be considered as the weighted sum of input excesses, bad output excesses and good output shortfalls, the corresponding description is specified as:

$\overrightarrow{S B M}(\mathbf{z} ; \boldsymbol{v})=\max \left\{\boldsymbol{v} \boldsymbol{s}:(\boldsymbol{z}+\boldsymbol{s})^{\prime}=\left(\boldsymbol{x}+\boldsymbol{s}_{\boldsymbol{x}}, \boldsymbol{y}+\boldsymbol{s}_{\boldsymbol{y}}, \boldsymbol{b}+\boldsymbol{s}_{\boldsymbol{b}}\right) \in \mathbb{T}^{\mathrm{SBM}}\right\}$

Here, $\boldsymbol{v}=\left(\boldsymbol{v}_{\boldsymbol{x}}, \boldsymbol{v}_{\boldsymbol{y}}, \boldsymbol{v}_{\boldsymbol{b}}\right) \in \mathfrak{R}_{+}^{N} \times \mathfrak{R}_{+}^{M} \times \mathfrak{R}_{+}^{B}$ is the exogenous weights assigned to various dimensional slacks which are collectively represented by the vector $\boldsymbol{s}=$ $\left(\boldsymbol{s}_{\boldsymbol{x}}, \boldsymbol{s}_{\boldsymbol{y}}, \boldsymbol{s}_{\boldsymbol{b}}\right)^{\prime}$. Similar to analysis in DDF, it is common to consider that $\boldsymbol{v}_{\boldsymbol{x}}<\mathbf{0}, \boldsymbol{v}_{\boldsymbol{y}}>$ $\mathbf{0}$, and $\boldsymbol{v}_{\boldsymbol{b}}<0$. Properties of the SBM of efficiency include:

D1: Translation: $\overrightarrow{S B M}(\mathbf{z}+\tau \boldsymbol{v} ; \boldsymbol{v})=\overrightarrow{S B M}(\mathbf{z} ; \boldsymbol{v})-\tau\left(\|\boldsymbol{v}\|_{2}\right)^{2}$.

D2: Homogeneity of degree one in $\boldsymbol{v}: \overrightarrow{S B M}(\mathbf{z} ; \tau \boldsymbol{v})=\tau \overrightarrow{S B M}(\mathbf{z} ; \boldsymbol{v})$.

D3: Input monotonicity: $\overrightarrow{S B M}(\breve{\boldsymbol{x}}, \boldsymbol{y}, \boldsymbol{b} ; \boldsymbol{v}) \geq \overrightarrow{S B M}(\boldsymbol{x}, \boldsymbol{y}, \boldsymbol{b} ; \boldsymbol{v})$ for $\breve{\boldsymbol{x}} \geq \boldsymbol{x}$.

D4: Good output monotonicity: $\overrightarrow{S B M}(\boldsymbol{x}, \breve{\boldsymbol{y}}, \boldsymbol{b} ; \boldsymbol{v}) \leq \overrightarrow{S B M}(\boldsymbol{x}, \boldsymbol{y}, \boldsymbol{b} ; \boldsymbol{v})$ for $\breve{\boldsymbol{y}} \geq \boldsymbol{y}$.

D5: Bad output monotonicity: $\overrightarrow{S B M}(\boldsymbol{x}, \boldsymbol{y}, \breve{\boldsymbol{b}} ; \boldsymbol{v}) \geq \overrightarrow{S B M}(\boldsymbol{x}, \boldsymbol{y}, \boldsymbol{b} ; \boldsymbol{v})$ for $\breve{\boldsymbol{b}} \geq \boldsymbol{b}$.

D6: Concavity: $\overrightarrow{S B M}(\boldsymbol{z} ; \boldsymbol{v})$ is concave in $\boldsymbol{z}+\boldsymbol{s} \in \mathbb{T}^{\mathbf{S B M}}$.

D7: Non-negativity: $\overrightarrow{S B M}(z ; \boldsymbol{v}) \geq 0$ if and only if $\boldsymbol{z}+\boldsymbol{s} \in \mathbb{T}^{\mathbf{S B M}}$.

Property D1 states that if inputs and bad outputs are contracted by $\tau\left(\left|\boldsymbol{v}_{\boldsymbol{x}}\right|,\left|\boldsymbol{v}_{\boldsymbol{b}}\right|\right)$ and good outputs are expanded by $\tau \boldsymbol{v}_{\boldsymbol{y}}$, then the value of the resulting slacks-based 
measure will be more efficient by the amount $\tau\left(\|v\|_{2}\right)^{2}$. Property D2 implies that a change in the unit of the weight vector does not affect the relative size of inefficiency. Property D3 is a monotonicity property corresponding to strong disposability of inputs, inefficiency will not decrease for a firm produces the same amount of outputs with more inputs. Likewise, D4 and D5 are monotonicity properties with respect to desirable and undesirable output(s). Property D6 is equivalent to say that $\mathbb{T}^{\text {SBM }}$ is convex and D7 indicates inefficiency cannot be negative.

\subsection{The dual relationship between DDF and $S B M$}

It is obvious that DDF and SBM share intuitively the same properties, the issue of choosing a particular direction towards the technological frontier is also one and the same (Chung et al. 1997; Chambers et al. 1998; Tone, 2001; Färe and Grosskopf, 2000; Färe et al. 2005; Fukuyama and Weber, 2009; and Hudgins and Primont, 2007). To illustrate the idea in a two-dimensional space, one could consider a simplified scenario with only one good output $(y)$ and one bad output $(b)$ for a fixed input vector $\boldsymbol{x}$, as presented in Figure 1. The collective vector $\boldsymbol{g}=\left(\mathbf{0}, g_{y}, g_{b}\right)^{\prime}$ represents the direction from an observed location A to a frontier location B; whereas in a slacksbased measure, the same direction from A to B would be represented by the weight vector $\boldsymbol{v}=\left(\mathbf{0}, v_{y}, v_{b}\right)$. Given an observation operating at point A, different directions will lead to different projection points onto the frontier, i.e. different Bs, therefore the distance from A to B will vary depends on the particular directional path being taken. The results from an efficiency benchmarking exercise won't be robust and comparable (Vardanyan and Noh, 2006; Agee et al. 2012; Pang and Deng, 2014; Atkinson and Tsionas, 2016) without an agreed direction.

\section{[Insert Figure 1 approximately here]}

As illustrated by Figure 1, $\tan \theta=g_{y} /\left|g_{b}\right|$ can be used to locate the projection direction in a DDF analysis. The larger $g_{y}$ is relative to $\left|g_{b}\right|$, the closer the direction 
is to $\overrightarrow{\mathrm{AC}}$; conversely, the smaller $g_{y}$ is relative to $\left|g_{b}\right|$, the closer the direction is to $\overrightarrow{\mathrm{AD}}$. In a SBM of efficiency, $v_{y}$ and $\left|v_{b}\right|$ indicate the preference degree of objective function to reductions in good-output and bad-output slacks. One can view the weight vector $\boldsymbol{v}$ as same as the direction vector $\boldsymbol{g}$ (Fukuyama and Weber, 2009). The larger $v_{y}$ is relative to $\left|v_{b}\right|$, the closer the direction is to $\overrightarrow{\mathrm{AC}}$ in a slacks-based measure; the smaller $v_{y}$ is relative to $\left|v_{b}\right|$, the closer the direction would be to $\overrightarrow{\mathrm{AD}}$.

Provided that the choice of a direction vector $\boldsymbol{g}$ in a DDF analysis is equivalent to the choice of the weight vector $\boldsymbol{v}$ in a SBM of efficiency, let's consider a DDF specified as below:

$$
\begin{aligned}
\vec{D}(z ; \boldsymbol{g})= & \max \left\{\beta:(\boldsymbol{z}+\beta \boldsymbol{g})^{\prime}=\left(\boldsymbol{x}+\beta \boldsymbol{g}_{\boldsymbol{x}}, \boldsymbol{y}+\beta \boldsymbol{g}_{\boldsymbol{y}}, \boldsymbol{b}+\beta \boldsymbol{g}_{\boldsymbol{b}}\right) \in \mathbb{T}^{\mathrm{DDF}}\right\} \\
\mathbb{T}^{\mathrm{DDF}}= & \left\{(\boldsymbol{x}, \boldsymbol{y}, \boldsymbol{b}): \sum_{k=1}^{K}\left(\rho^{k} \boldsymbol{x}^{k}\right) \leq \boldsymbol{x} ; \quad \sum_{k=1}^{K}\left(\rho^{k} \boldsymbol{y}^{k}\right) \geq \boldsymbol{y} ; \quad \sum_{k=1}^{K}\left(\rho^{k} \boldsymbol{b}^{k}\right) \leq \boldsymbol{b} ; \boldsymbol{\rho}=\right. \\
& \left.\left(\rho^{1}, \cdots, \rho^{K}\right) \geq 0,\|\boldsymbol{\rho}\|_{1}=1\right\} .
\end{aligned}
$$

One can simultaneously specify a SBM as:

$$
\begin{gathered}
\overrightarrow{S B M}(\boldsymbol{z} ; \boldsymbol{v})=\max \left\{\boldsymbol{v s}:(\boldsymbol{z}+\boldsymbol{s})^{\prime}=\left(\boldsymbol{x}+\boldsymbol{s}_{\boldsymbol{x}}, \boldsymbol{y}+\boldsymbol{s}_{\boldsymbol{y}}, \boldsymbol{b}+\boldsymbol{s}_{\boldsymbol{b}}\right) \in \mathbb{T}^{\mathbf{S B M}}\right\} \\
\mathbb{T}^{\mathrm{SBM}}=\left\{(\boldsymbol{x}, \boldsymbol{y}, \boldsymbol{b}): \sum_{k=1}^{K}\left(\rho^{k} \boldsymbol{x}^{k}\right) \leq \boldsymbol{x} ; \sum_{k=1}^{K}\left(\rho^{k} \boldsymbol{y}^{k}\right) \geq \boldsymbol{y} ; \sum_{k=1}^{K}\left(\rho^{k} \boldsymbol{b}^{k}\right) \leq\right. \\
\left.\boldsymbol{b} ; \boldsymbol{\rho}=\left(\rho^{1}, \cdots, \rho^{K}\right) \geq 0,\|\boldsymbol{\rho}\|_{1}=1\right\},
\end{gathered}
$$

where $K$ is the number of observations or decision making units (DMUs), $\boldsymbol{z}^{k}=$ $\left(\boldsymbol{x}^{k}, \boldsymbol{y}^{k}, \boldsymbol{b}^{k}\right)^{\prime}$ is the collective input and output vector for observation $k=1,2, \cdots, K$. The sign of inequality in $\sum_{k=1}^{K}\left(\rho^{k} \boldsymbol{b}^{k}\right) \leq \boldsymbol{b}$ is often replaced by equality (Boyd et al. 2002; Pang and Deng, 2014), but this makes no difference to the results of the analysis.

For a given direction vector $\boldsymbol{g}$, the specifications provided by (2.5) and (2.6) would be equivalent if the following two supplementary conditions have been imposed on the weight vector $\boldsymbol{v}$ : 
$s=\left(s_{x}, s_{y}, s_{b}\right)^{\prime} \| \boldsymbol{g}=\left(g_{x}, g_{y}, g_{b}\right)^{\prime}$,

$\boldsymbol{v g}=1$

Equation (2.7) means the collective slacks vector $\boldsymbol{s}$ and the direction vector $\boldsymbol{g}$ are parallel to each other. Equation (2.8) implies that the inner product of vector $\boldsymbol{v}^{\prime}$ and $\boldsymbol{g}$ equals to unity, so the weight vector and direction vector cannot be vertical. ${ }^{8}$ For a DDF with a particular direction vector $\boldsymbol{g}$, one can always find an equivalent SBM by incorporating (2.7) and (2.8) into the constraints of specifying the $\mathbb{T}^{\text {SBM }}$. Conversely, for a SBM with a specific weight vector $\boldsymbol{v}$, one can always find the corresponding equivalent DDF by including the same constraints in $\mathbb{T}^{\mathrm{DDF}}$. In other words, the problem of setting a direction vector $\boldsymbol{g}$ in DDF can always be converted to choosing a weight vector $\boldsymbol{v}$ in SBM.

Table 1 presents eight common directional settings, where $\boldsymbol{g}=(\mathbf{0}, \boldsymbol{y},-\boldsymbol{b})^{\prime}$ is the most frequently adopted choice in the literature; $\boldsymbol{g}=(-\boldsymbol{x}, \mathbf{0}, \mathbf{0})^{\prime}, \boldsymbol{g}=(\mathbf{0}, \boldsymbol{y}, \mathbf{0})^{\prime}$ or $\boldsymbol{g}=(\mathbf{0}, \mathbf{0},-\boldsymbol{b})^{\prime}$ are equivalent to the conventional DEA analysis with either inputs orientation, good outputs orientation, or bad outputs orientation; $\boldsymbol{g}=\left(-\boldsymbol{\psi}_{x} \odot\right.$ $\left.\boldsymbol{x}, \boldsymbol{\psi}_{\boldsymbol{y}} \odot \boldsymbol{y},-\boldsymbol{\psi}_{\boldsymbol{b}} \odot \boldsymbol{b}\right)^{\prime}$ where $\left\|\boldsymbol{\psi}_{\boldsymbol{x}}\right\|_{1}+\left\|\boldsymbol{\psi}_{\boldsymbol{y}}\right\|_{1}+\left\|\boldsymbol{\psi}_{\boldsymbol{b}}\right\|_{1}=1$ is equivalent to the conventional SBM model (Fukuyama and Weber, 2009; Krüger, 2017), therefore it does not deal with the issue of finding the optimal weight vector in a SBM either. Moreover, the first three directional choices are generally considered to be exogenous (Chambers et al. 1996; Charnes et al. 1978; Färe et al. 2005, 2006; Feng and Serletis, 2014), which lack appropriate theoretical justification but the programs are relatively easy to solve. The rest considers the choice of direction as endogenous, and it is determined through common behavioral assumption such as (marginal) profit maximization. The resulting mathematical program is however more complicated to solve. This study attempts to find an optimal solution for endogenous directional

\footnotetext{
8 Proof of equation (2.8) is provided in Appendix 3.
} 
choice without relying on price information but utilizes the potential correlation between observations.

[Insert Table 1 approximately here]

\section{The Factor-Analysis-Based Directional Distance Function (FAB-DDF)}

\subsection{The factor-analysis-based distance measure}

Let us denote the distance from an observed location A to its projection onto the frontier location B as $\|B-A\|=\|\boldsymbol{s}\|$, where $\boldsymbol{s}=\left(\boldsymbol{s}_{\boldsymbol{x}}, \boldsymbol{s}_{\boldsymbol{y}}, \boldsymbol{s}_{\boldsymbol{b}}\right)^{\prime} \in \mathfrak{R}_{+}^{N} \times \mathfrak{R}_{+}^{M} \times \mathfrak{R}_{+}^{B}$ is the collective vector of slacks associated with all inputs and outputs, and $\boldsymbol{s}_{\boldsymbol{y}} \geq \mathbf{0}$, $\boldsymbol{s}_{\boldsymbol{x}} \leq \mathbf{0}$, and $\boldsymbol{s}_{\boldsymbol{b}} \leq \mathbf{0}$. In the slacks-based measure specified by equation (2.6), this distance is provided by $\|\boldsymbol{s}\|_{C}=\boldsymbol{v} \cdot \boldsymbol{s}$ with an exogenously preassigned weight vector $\boldsymbol{v}$. For example, the slacks-based measure in Fukuyama and Weber (2009) sets the following:

$\boldsymbol{v}=\left(\frac{-1}{2 N} \frac{1}{x_{1}}, \cdots, \frac{-1}{2 N} \frac{1}{x_{N}}, \frac{1}{2(M+B)} \frac{1}{y_{1}}, \cdots, \frac{1}{2(M+B)} \frac{1}{y_{M}}, \frac{-1}{2(M+B)} \frac{1}{b_{1}}, \cdots, \frac{-1}{2(M+B)} \frac{1}{b_{B}}\right)$.

Next let us consider two alternative measures of distance:

The Euclidean distance $\|\boldsymbol{s}\|_{E}=\left(\boldsymbol{s}^{\prime} \boldsymbol{s}\right)^{1 / 2}$,

The Mahalanobis distance $\|\boldsymbol{s}\|_{M}=\left(\boldsymbol{s}^{\prime} \boldsymbol{\Sigma}^{-1} \boldsymbol{s}\right)^{1 / 2}$,

with $\boldsymbol{\Sigma}$ represents the input-output covariance matrix.

An optimal direction in DDF is defined in Petersen (2018) by minimizing the Euclidean distance between the observed location A and the efficient frontier B with a two-stage nonlinear approach. The Mahalanobis distance is often preferred because it is unitless and scale-invariant through the incorporation of the correlation structure in the data set. However, it is a nonlinear combination of the distances (slacks) in various dimensions, the task of solving the corresponding nonlinear programming problem is a nontrivial one. Nonetheless, as a weighted distance it makes the slacks 
from various dimensions comparable. In other words, it reduces the multi-dimensional input-output vector $\boldsymbol{z}=(\boldsymbol{x}, \boldsymbol{y}, \boldsymbol{b})^{\prime} \in \mathfrak{R}_{+}^{N} \times \mathfrak{R}_{+}^{M} \times \mathfrak{R}_{+}^{B}$ into a one dimensional scalar measure.

The core idea behind the factor analysis is similar, which is the approximation of the covariance matrix $\Sigma$ (Johnson and Wichern, 2013). A typical linear factor analysis equation can be specified as:

$\boldsymbol{z}_{(N+M+B) \times 1}=\boldsymbol{\mu}_{(N+M+B) \times 1}+\boldsymbol{L}_{(N+M+B) \times Q} \boldsymbol{F}_{Q \times 1}+\boldsymbol{\varepsilon}_{(N+M+B) \times 1}$,

where $\mu_{i}$ is the mean of variable $i$ across all observations; $\boldsymbol{L}$ is the loading matrix; $F_{i}$ is the $i$ th common factor; $Q \leq N+M+B$ is the number of common factors; $\varepsilon_{i}$ is the $i$ th specific factor; $\boldsymbol{F}$ and $\boldsymbol{\varepsilon}$ are independent; $\mathbb{E}(\boldsymbol{F})=\mathbf{0}, \operatorname{Cov}(\boldsymbol{F})=\boldsymbol{I}$; $\mathbb{E}(\boldsymbol{\varepsilon})=\mathbf{0}, \operatorname{Cov}(\boldsymbol{\varepsilon})=\boldsymbol{\Psi}$, where $\boldsymbol{\Psi}$ is a diagonal matrix; the relationships of $\boldsymbol{\Sigma}=$ $\operatorname{Cov}(\mathbf{z})=\boldsymbol{L} \boldsymbol{L}^{\prime}+\boldsymbol{\Psi}$ and $\operatorname{Cov}(\mathbf{z}, \boldsymbol{F})=\boldsymbol{L}$ can be obtained easily, where the covariance matrix $\boldsymbol{\Sigma}$ is a nonsingular matrix.

There is information loss if $Q<N+M+B$ because the original data is of dimensions $N+M+B$, and the information loss can be measured by the specific factors. In order to figure out the weights for comparing distances in various dimensions, we set $Q=N+M+B$ instead of simply reducing the dimensions. Since $\boldsymbol{\Sigma}$ is nonsingular, one can always find $N+M+B$ common factors. Given $Q=N+M+B$, consider $\boldsymbol{\varepsilon}=\mathbf{0}$ and $\boldsymbol{\Psi}=\mathbf{0}$ for now, equation (3.4) can be simplified into the following:

$\boldsymbol{z}_{(N+M+B) \times 1}=\boldsymbol{\mu}_{(N+M+B) \times 1}+\boldsymbol{L}_{(N+M+B) \times(N+M+B)} \boldsymbol{F}_{(N+M+B) \times 1}$,

where $\boldsymbol{\Sigma}=\boldsymbol{L} \boldsymbol{L}^{\prime}$. There are $N+M+B$ eigenvalues, referred to as $\lambda_{1} \geq \lambda_{2} \geq \cdots \geq$ $\lambda_{N+M+B} \geq 0$, and their corresponding normalized eigenvectors are $\boldsymbol{e}_{i}$ ( $i=$ $1, \cdots, N+M+B)$. The following can be obtained by factoring the covariance matrix: 


$$
\begin{aligned}
\boldsymbol{\Sigma} & =\lambda_{1} \boldsymbol{e}_{1} \boldsymbol{e}_{1}^{\prime}+\cdots+\lambda_{N+M+B} \boldsymbol{e}_{N+M+B} \boldsymbol{e}_{N+M+B}^{\prime} \\
& =\left[\sqrt{\lambda_{1}} \boldsymbol{e}_{1}, \cdots, \sqrt{\lambda_{N+M+B}} \boldsymbol{e}_{N+M+B}\right]\left[\begin{array}{c}
\sqrt{\lambda_{1}} \boldsymbol{e}_{1}^{\prime} \\
\vdots \\
\sqrt{\lambda_{N+M+B}} \boldsymbol{e}_{N+M+B}^{\prime}
\end{array}\right] .
\end{aligned}
$$

From (3.6) and $\boldsymbol{\Sigma}=\boldsymbol{L} \boldsymbol{L}^{\prime}$, we have:

$$
\boldsymbol{L}=\left[\sqrt{\lambda_{1}} \boldsymbol{e}_{1}, \cdots, \sqrt{\lambda_{N+M+B}} \boldsymbol{e}_{N+M+B}\right]
$$

In summary, the sample means computed from the observed data $\boldsymbol{z}$ can be used to estimate $\boldsymbol{\mu}$; and the eigenvalues and eigenvectors of sample covariance matrix can be used to estimate $\boldsymbol{L}$; so the common factors $\boldsymbol{F}=\left(F_{1}, \cdots, F_{N+M+B}\right)$ can be obtained by equation (3.5), that is, $\boldsymbol{F}=\boldsymbol{L}^{-1}(\boldsymbol{z}-\boldsymbol{\mu})$. Because $\boldsymbol{L}$ is composed by mutually perpendicular eigenvectors, its inverse matrix always exists.

When the units of the variables are not comparable, researchers usually standardize with $\tilde{\boldsymbol{z}}=\left(\frac{z_{1}-\bar{z}_{1}}{\sqrt{\sigma_{11}}}, \cdots, \frac{z_{N+M+B}-\bar{z}_{N+M+B}}{\sqrt{\sigma_{N+M+B, N+M+B}}}\right)^{\prime}$, where $\bar{z}_{i}$ and $\sqrt{\sigma_{i i}}$ are the sample mean and standard deviation of variable $i$. After standardization, $\widetilde{\boldsymbol{\mu}}=\mathbf{0}$ and $\widetilde{\boldsymbol{F}}=\widetilde{\boldsymbol{L}}^{-1} \widetilde{\boldsymbol{z}}$, where $\tilde{\boldsymbol{L}}=\left[\sqrt{\tilde{\lambda}_{1}} \tilde{\boldsymbol{e}}_{1}, \cdots, \sqrt{\tilde{\lambda}_{N+M+B}} \tilde{\boldsymbol{e}}_{N+M+B}\right]$ and $\widetilde{\boldsymbol{\Sigma}}=\tilde{\boldsymbol{L}} \tilde{\boldsymbol{L}}^{\prime}$ is the sample correlation matrix. Let's denote the element of matrix $\tilde{\boldsymbol{L}}^{-1}$ as $\alpha_{i j}$. According to $\widetilde{\boldsymbol{F}}=\tilde{\boldsymbol{L}}^{-1} \tilde{\mathbf{z}}$,

$$
\begin{gathered}
\tilde{F}_{1}=\alpha_{11} \tilde{z}_{1}+\alpha_{12} \tilde{z}_{2}+\cdots+\alpha_{1, N+M+B} \tilde{z}_{N+M+B} \\
\tilde{F}_{2}=\alpha_{21} \tilde{z}_{1}+\alpha_{22} \tilde{z}_{2}+\cdots+\alpha_{2, N+M+B} \tilde{z}_{N+M+B} \\
\vdots \\
\tilde{F}_{N+M+B}=\alpha_{N+M+B, 1} \tilde{z}_{1}+\alpha_{N+M+B, 2} \tilde{z}_{2}+\cdots+\alpha_{N+M+B, N+M+B} \tilde{z}_{N+M+B}
\end{gathered}
$$

As demonstrated in Appendix 4, the variance contribution rate of factor $\tilde{F}_{i}$ is $\frac{\widetilde{\lambda}_{i}}{N+M+B}$. And $\tilde{F}_{T}=\sum_{i=1}^{N+M+B} \frac{\widetilde{\lambda}_{i} \tilde{F}_{i}}{N+M+B}$ represents a comprehensive score, which is a common dimensionality reduction strategy in the field of factor analysis. Considering the variance decomposition of factor $\tilde{F}_{i}$, we can obtain: 
$\operatorname{Var}\left(\tilde{F}_{i}\right)=\sum_{j=1}^{N+M+B} \alpha_{i j} \operatorname{Cov}\left(\tilde{z}_{j}, \tilde{F}_{i}\right)=1 .^{9}$

Therefore, $\alpha_{i j} \operatorname{Cov}\left(\tilde{z}_{j}, \tilde{F}_{i}\right)$ indicates the importance of variable $\tilde{z}_{j}$ to factor $\tilde{F}_{i}$.

Similarly, one can obtain $\operatorname{Var}\left(\widetilde{F}_{T}\right)=\sum_{i=1}^{N+M+B} \frac{\widetilde{\lambda}_{i}}{N+M+B} \operatorname{Cov}\left(\widetilde{F}_{i}, \widetilde{F}_{T}\right)$ considering the variance decomposition of $\tilde{F}_{T}$, i.e. $\sum_{i=1}^{N+M+B} \frac{\tilde{\lambda}_{i}}{N+M+B} \frac{\operatorname{Cov}\left(\tilde{F}_{i}, \tilde{F}_{T}\right)}{\operatorname{Var}\left(\tilde{F}_{T}\right)}=1$. Therefore, $\frac{\widetilde{\lambda}_{i}}{N+M+B} \frac{\operatorname{Cov}\left(\tilde{F}_{i}, \tilde{F}_{T}\right)}{\operatorname{Var}\left(\tilde{F}_{T}\right)}$ indicates the importance of factor $\tilde{F}_{i}$ to comprehensive score $\tilde{F}_{T}$.

Taking into account the importance of $\tilde{z}_{j}$ to factor $\tilde{F}_{i}$ and the importance of $\tilde{F}_{i}$ to comprehensive score $\tilde{F}_{T}, \sum_{i=1}^{N+M+B} \frac{\tilde{\lambda}_{i} \alpha_{i j}}{N+M+B} \frac{\operatorname{Cov}\left(\tilde{F}_{i}, \tilde{F}_{T}\right) \operatorname{Cov}\left(\tilde{z}_{j}, \tilde{F}_{i}\right)}{\operatorname{Var}\left(\tilde{F}_{T}\right)}$ indicates the importance of $\tilde{z}_{j}$ to $\tilde{F}_{T}$. Thus the weights $\sum_{i=1}^{N+M+B} \frac{\widetilde{\lambda}_{i} \alpha_{i j}}{N+M+B} \frac{\operatorname{Cov}\left(\tilde{F}_{i}, \tilde{F}_{T}\right) \operatorname{Cov}\left(\tilde{z}_{j}, \tilde{F}_{i}\right)}{\operatorname{Var}\left(\tilde{F}_{T}\right)}(j=1, \cdots, N+$ $M+B)$ can be used to weigh the distances $\left(\left|s_{j}\right|\right)$ in various dimensions to obtain an average distance, that is:

$$
\|\boldsymbol{s}\|_{C}=\boldsymbol{v} \cdot \boldsymbol{s}=\left(\cdots \sum_{i=1}^{N+M+B} \frac{\widetilde{\lambda}_{i} \alpha_{i j}}{N+M+B} \frac{\operatorname{Cov}\left(\tilde{F}_{i}, \tilde{F}_{T}\right) \operatorname{Cov}\left(\tilde{z}_{j}, \tilde{F}_{i}\right) \operatorname{Sig}\left(s_{j}\right)}{\operatorname{Var}\left(\tilde{F}_{T}\right)} \cdots\right)_{(N+M+B) \times 1} \cdot \boldsymbol{s}
$$

where $\operatorname{Sig}\left(s_{j}\right)=-1$ if $s_{j}<0$ and $\operatorname{Sig}\left(s_{i}\right)=+1$ if $s_{j} \geq 0$. The sum of the weights equals to 1, i.e. $\sum_{j=1}^{N+M+B} \sum_{i=1}^{N+M+B} \frac{\tilde{\lambda}_{i} \alpha_{i j}}{N+M+B} \frac{\operatorname{Cov}\left(\tilde{F}_{i}, \tilde{F}_{T}\right) \operatorname{Cov}\left(\tilde{z}_{j}, \tilde{F}_{i}\right)}{\operatorname{Var}\left(\tilde{F}_{T}\right)}=1 .^{10}$

This weighting method, as specified by equation (3.10), has several advantages: (1) same as the Mahalanobis distance, it is unitless, scale-invariant, and accounts for the correlation structure of the data set; but (2) unlike the Mahalanobis distance and Euclidean distance, it is linear. The corresponding slacks-based measure is therefore easy to solve; (3) it uses common factors that are mutually perpendicular to explain

\footnotetext{
9 View $\tilde{F}_{i}$ as an investment portfolio of $\tilde{z}_{j}, j=1, \cdots, N+M+B$, then according to the capital asset pricing model $\operatorname{Cov}\left(\tilde{z}_{j}, \tilde{F}_{i}\right)$ is the Beta coefficient of $\tilde{z}_{j}$ that measures the systematic risk of $\tilde{z}_{j}$, and $\sum_{j=1}^{N+M+B} \alpha_{i j} \operatorname{Cov}\left(\tilde{z}_{j}, \tilde{F}_{i}\right)$ is the Beta coefficient of the investment portfolio.

${ }^{10} \sum_{j=1}^{N+M+B} \sum_{i=1}^{N+M+B} \frac{\tilde{\lambda}_{i}}{N+M+B} \frac{\operatorname{Cov}\left(\tilde{F}_{i}, \tilde{F}_{T}\right) \alpha_{i j} \operatorname{Cov}\left(\tilde{z}_{j}, \tilde{F}_{i}\right)}{\operatorname{Var}\left(\tilde{F}_{T}\right)}=\sum_{i=1}^{N+M+B} \frac{\tilde{\lambda}_{i}}{N+M+B} \frac{\operatorname{Cov}\left(\tilde{F}_{i} \tilde{F}_{T}\right)}{\operatorname{Var}\left(\tilde{F}_{T}\right)} \sum_{j=1}^{N+M+B} \alpha_{i j} \operatorname{Cov}\left(\tilde{z}_{j}, \tilde{F}_{i}\right)=1$.
} 
the relative importance of variables (i.e. inputs and outputs). Due to the desirable statistical properties processed by the common factors, distances in different dimensions are comparable after adjusting the variables with the common factors; and (4) compared to conventional factor-based analysis, we set the number of common factors equal to the rank of the covariance matrix to prevent information loss, i.e. $\boldsymbol{\Sigma}=$ $\boldsymbol{L L}^{\prime}\left(\right.$ or $\left.\widetilde{\boldsymbol{\Sigma}}=\tilde{\boldsymbol{L}} \widetilde{\boldsymbol{L}}^{\prime}\right)$

One particular caveat is that even though relative distance is commonly used, we are not able to define the weighted distance of slacks as the following:

$\left\|\tilde{\mathbf{z}}^{r} \odot \boldsymbol{s}\right\|_{C}=\boldsymbol{v}\left(\tilde{\mathbf{z}}^{r} \odot \boldsymbol{s}\right)=\sum_{j=1}^{N+M+B} \sum_{i=1}^{N+M+B} \frac{\tilde{\lambda}_{i} \alpha_{i j}}{N+M+B} \frac{\operatorname{Cov}\left(\tilde{F}_{i}, \tilde{F}_{T}\right) \operatorname{Cov}\left(\tilde{z}_{j}, \tilde{F}_{i}\right) \operatorname{Sig}\left(s_{j}\right)}{\operatorname{Var}\left(\tilde{F}_{T}\right)} \frac{s_{j}}{\tilde{z}_{j}}$

where $\tilde{\mathbf{z}}^{r}=\left(\frac{\mathbf{1}}{\tilde{z}_{1}}, \cdots, \frac{\mathbf{1}}{\tilde{z}_{N+M+B}}\right)^{\prime}$ and $\odot$ denotes the Hadamard product of two vectors. This is because the standardized $\tilde{z}_{j}$ could be negative. The following can be specified instead:

$$
\tilde{\mathbf{z}}^{r r}=\left(\frac{\sqrt{\sigma_{11}}}{z_{1}}, \cdots, \frac{\sqrt{\sigma_{N+M+B, N+M+B}}}{z_{N+M+B}}\right)^{\prime}
$$

and we can calculate:

$$
\begin{aligned}
\| \tilde{\boldsymbol{z}}^{r \boldsymbol{r}} & \odot \boldsymbol{s} \|_{C}=\boldsymbol{v}\left(\tilde{\boldsymbol{z}}^{\boldsymbol{r r}} \odot \boldsymbol{s}\right) \\
& =\sum_{j=1}^{N+M+B} \sum_{i=1}^{N+M+B} \frac{\widetilde{\lambda}_{i} \alpha_{i j}}{N+M+B} \frac{\operatorname{Cov}\left(\tilde{F}_{i}, \tilde{F}_{T}\right) \operatorname{Cov}\left(\tilde{z}_{j}, \tilde{F}_{i}\right) \sqrt{\sigma_{j j}} \operatorname{Sig}\left(s_{j}\right)}{\operatorname{Var}\left(\tilde{F}_{T}\right)} \frac{s_{j}}{z_{j}} .
\end{aligned}
$$

$\left\|\tilde{\boldsymbol{z}}^{r \boldsymbol{r}} \odot \boldsymbol{S}\right\|_{C}$ can be interpreted as using $\sum_{i=1}^{N+M+B} \frac{\tilde{\lambda}_{i} \alpha_{i j}}{N+M+B} \frac{\operatorname{Cov}\left(\tilde{F}_{i}, \tilde{F}_{T}\right) \operatorname{Cov}\left(\tilde{z}_{j}, \tilde{F}_{i}\right) \sqrt{\sigma_{j j}} \operatorname{Sig}\left(s_{j}\right)}{\operatorname{Var}\left(\tilde{F}_{T}\right)} \frac{1}{z_{j}}$ to weigh the absolute distance $s_{j}$, or using $\sum_{i=1}^{N+M+B} \frac{\tilde{\lambda}_{i} \alpha_{i j}}{N+M+B} \frac{\operatorname{Cov}\left(\tilde{F}_{i}, \tilde{F}_{T}\right) \operatorname{Cov}\left(\tilde{z}_{j}, \tilde{F}_{i}\right) \operatorname{Sig}\left(s_{j}\right)}{\operatorname{Var}\left(\tilde{F}_{T}\right)}$ to weigh the relative distance $\frac{\sqrt{\sigma_{j j}} s_{j}}{z_{j}}$.

\subsection{The factor-analysis-based DDF with an endogenous direction}

To sum up, the development of this new approach is based primarily on the utilization of factor analysis in determining the optimal weight vector $\boldsymbol{v}$. The resulting weighted 
distance, i.e. $\boldsymbol{v} \cdot \boldsymbol{s}$, is then used as the objective function in a SBM of efficiency. Because of the dualities between DDF and SBM, one can obtain the direction vector $\boldsymbol{g}$ corresponding to the optimal weight vector $\boldsymbol{v}$. The resulting DDF analysis is therefore called the FAB-DDF in which not only the selection of direction is endogenous but also the reliance on any exogenous settings or price information is unnecessary. The specific steps involved in the application of this FAB-DDF can be summarized below:

Step 1. Standardize all the input-output variables $\boldsymbol{z}$ by $\tilde{\boldsymbol{z}}=\left(\frac{z_{1}-\bar{z}_{1}}{\sqrt{\sigma_{11}}}, \cdots, \frac{z_{N+M+B}-\bar{z}_{N+M+B}}{\sqrt{\sigma_{N+M+B, N+M+B}}}\right)^{\prime}$;

Step 2. Determine the optimal weight vector $\boldsymbol{v}$ in the SBM using factor analysis:

2.1 use the standardized sample data to obtain the sample correlation matrix $\widetilde{\boldsymbol{\Sigma}}$;

2.2 calculate the eigenvalues and eigenvectors of $\widetilde{\boldsymbol{\Sigma}}$, i.e. $\left(\tilde{\lambda}_{i} ; \tilde{\boldsymbol{e}}_{i}\right)$ where $i=1, \cdots, N+M+B$;

2.3 calculate the inverse matrix of $\tilde{\boldsymbol{L}}=\left[\sqrt{\tilde{\lambda}_{1}} \tilde{\boldsymbol{e}}_{1}, \cdots, \sqrt{\tilde{\lambda}_{N+M+B}} \tilde{\boldsymbol{e}}_{N+M+B}\right]$ to obtain the elements of matrix $\tilde{\boldsymbol{L}}^{-1}$, i.e. $\alpha_{i j}$;

2.4 calculate the common factors $\tilde{F}_{i}(i=1, \cdots, N+M+B)$ and comprehensive factor $\tilde{F}_{T}$ using the factor analysis approach; and

2.5 obtain the distance weights, $v_{j}=\sum_{i=1}^{N+M+B} \frac{\widetilde{\lambda}_{i} \alpha_{i j}}{N+M+B} \frac{\operatorname{Cov}\left(\tilde{F}_{i}, \tilde{F}_{T}\right) \operatorname{Cov}\left(\tilde{z}_{j}, \tilde{F}_{i}\right) \sqrt{\sigma_{j j}} \operatorname{Sig}\left(s_{j}\right)}{\operatorname{Var}\left(\tilde{F}_{T}\right)} \frac{1}{z_{j}}$.

Step 3. Solve the SBM model (i.e. equation (2.6)) using the weight vector $\boldsymbol{v}$ obtained from the previous step.

Step 4. Based on the results obtained, further solve for the optimal directional vector $\boldsymbol{g}$ using equations (2.7) and (2.8). Substituting this direction vector $\boldsymbol{g}$ into the conventional DDF analysis (i.e. equation (2.5)) with the standardized input-output vector $\tilde{\mathbf{z}}$, identical efficiency scores as to the SBM model can be obtained.

If one only cares about the efficiency scores, there is no need to proceed with Step 4, the purpose of which is to solve the direction selection problem in case the DDF analysis has been chosen as the preferred approach.

\section{Efficiency Analysis of New Zealand Hospitals}

\subsection{Data sources and description}


The data used in this study are provided by the Ministry of Health $(\mathrm{MOH})$, which contains input information for each local DHB in the form of monthly financial statements during the year 2011-2017. We constructed four inputs (the number of full time equivalent (FTE) medical doctors, nurses, other staff, and capital), two good outputs (case-weighted inpatient discharges and price-weighted outpatient visits), and one bad output (readmission within 28 days of discharge) to implement this new FABDDF model.

A multiple-step procedure is followed to derive measures that can more accurately reflect input volumes. In the first stage, we estimate the price of medical service by taking the ratio of payments made to employed medical staff to the total FTE doctors on the payroll. There is no equivalent FTE counts for doctors who are outsourced from private practices so the monetary expenses on outsourced medical is often used for this purpose. The problem is that the monthly expenditures on outsourced inputs often contain negative values as a result of balancing the accounts, any input volume measures derived from such financial accounts are unlikely to represent the actual usage, and there is no way to ascertain this deviation. One solution is to aggregate the monthly expenditures on outsourced medical over the whole financial year. The FTE counts for outsourced medical can now be estimated by taking the ratio of this aggregate expenditures and the price of medical service (estimated in the first stage for employed medical), assuming both hired medical and outsourced medical doctors receive similar remuneration. The final FTE counts are the sum of employed medical and estimated outsourced medical.

The total FTE counts for nurses and other staff are derived in the same way. Other staff is a weighted sum of allied professional staff, support staff and management staff. The weights used are the expenditure shares for each category.

Capital is often more challenge to measure due to the lack of data to separate the flow 
of capital services from capital stock. The number of installed beds is a common proxy variable for capital input (Aletras et al. 2007; Ancarani et al. 2009; Brown, 2003; Chang et al. 2004; Friesner et al. 2013; Herr, 2008; Herr et al. 2011; Worthington, 2004). Unfortunately, that information for NZ DHB was not consistently collected. Others resort to use measures like depreciation (Marcinko and Hetico, 2012; Zelman et al. 2009) and capital charges (Parkin and Hollingsworth, 1997). Depreciation intends to measure the reduction in the value of capital assets and is calculated using the straight-line method (i.e. assets depreciate by the same percentage each year) in NZ. Capital charges is considered to be the best proxy because it reflects the opportunity cost of capital employed in public health services (NZ Productivity Commission, 2017).

Output information is extracted from the National Minimum Hospital Datasets (NMDS) and National Non-Admitted Patient Collection (NNPAC) by the MOH. Two desirable output measures are used to reflect the full range of hospital services provided: case-weighted inpatient discharges and price-weighted outpatient visits. As mentioned previously, public hospitals in NZ are run and owned by DHBs to provide a variety of publicly funded health and disability services, they can be broadly categorized into inpatient admissions and outpatient visits. Although detailed case information is available for both categories (such as maternity, medical and surgical cases), the use of which comes at the cost of losing more degrees of freedom in such a small census dataset. Provided inpatient discharges have been adjusted using the casemix methodology which accounts for the complexity of the diagnosis as well as the relative resources for treatment, the resulting output measures are reasonably comparable across different hospitals in different DHBs (Fraser and Nolan, 2017). Outpatient visits have been weighted with national prices (from the National Cost Collection and Pricing Programme) which are calculated for the purpose of interdistrict flows. There are potentially two measures of undesirable outputs: adverse 
events ${ }^{11}$ and readmissions. The former is identified and reported by each DHB on a voluntary basis, implying it does not count as an objective measure comparable across observations. As a result, we considered hospital readmissions within 28 days of discharge as an indicator for undesirable output.

The final dataset is a balanced panel containing 20 observations (all DHBs) each year, for the year 2011-2017. Descriptive statistics of the variables for each DHB are presented in Table 2. There are three DHBs in the city of Auckland serving over one third of the national population together, they are Counties Manukau DHB, Waitemata DHB, and Auckland DHB. Counties Manukau has the highest average number of outpatient-visit $(29,923)$. Auckland generates the highest average number of inpatientdischarge $(130,053)$, the associated undesirable outcomes are also the highest (77 selfreported adverse events and 14,786 readmissions).

[Insert Table 2 approximately here]

\subsection{Efficiency evaluation}

\section{Direction selection}

During the first step of implementing this new FAB-DDF, the collective input-output vector $\boldsymbol{z}$ is standardized by $\tilde{\boldsymbol{z}}=\left(\frac{z_{1}-\bar{z}_{1}}{\sqrt{\sigma_{11}}}, \cdots, \frac{z_{7}-\bar{z}_{7}}{\sqrt{\sigma_{77}}}\right)^{\prime}$ and the sample correlation matrix $\widetilde{\boldsymbol{\Sigma}}$ is obtained. The Kaiser-Meyer-Olkin measure of sampling adequacy is 0.865 , and the Bartlett's test of sphericity is significant at $0.1 \%$. These indicate that the factor analysis based on this dataset is adequate. There are 7 eigenvalues of $\widetilde{\boldsymbol{\Sigma}}$ : $\tilde{\lambda}_{1}=6.5318, \tilde{\lambda}_{2}=0.2731, \tilde{\lambda}_{3}=0.0930, \tilde{\lambda}_{4}=0.0474, \tilde{\lambda}_{5}=0.0379, \tilde{\lambda}_{6}=$ 0.0097, and $\tilde{\lambda}_{7}=0.0072$. The corresponding eigenvectors being selected are:

\footnotetext{
11 Adverse events are cases that involve serious harm or death. They are categorized into (1) harm from falls; (2) clinical management events such as delays in treatment, concerns about the accuracy of diagnosis, inadequate patient monitoring; and (3) medical overdose and surgical site infections.
} 
$\left(\begin{array}{llllllll}\tilde{\boldsymbol{e}}_{1} & \tilde{\boldsymbol{e}}_{2} & \tilde{\boldsymbol{e}}_{3} & \tilde{\boldsymbol{e}}_{4} & \tilde{\boldsymbol{e}}_{5} & \tilde{\boldsymbol{e}}_{6} & \tilde{\boldsymbol{e}}_{7}\end{array}\right)=\left[\begin{array}{cccccccc}0.3837 & 0.2017 & 0.2897 & 0.1670 & 0.6378 & 0.5156 & 0.1662 \\ 0.3828 & -0.2451 & 0.4593 & -0.1718 & -0.2097 & -0.3350 & 0.6298 \\ 0.3864 & -0.0501 & 0.1988 & -0.3992 & -0.4907 & 0.4892 & -0.4113 \\ 0.3570 & 0.7452 & -0.2857 & 0.2534 & -0.3604 & -0.0915 & 0.1819 \\ 0.3666 & -0.5786 & -0.3863 & 0.5791 & -0.1463 & 0.1556 & 0.0258 \\ 0.3880 & 0.0281 & 0.2767 & 0.1970 & 0.1985 & -0.5682 & -0.6091 \\ 0.3802 & -0.0765 & -0.5985 & -0.5872 & 0.3431 & -0.1646 & 0.0422\end{array}\right]$.

The matrix $\tilde{\boldsymbol{L}}=\left[\sqrt{\tilde{\lambda}_{1}} \tilde{\boldsymbol{e}}_{1}, \cdots, \sqrt{\tilde{\lambda}_{N+M+B}} \tilde{\boldsymbol{e}}_{N+M+B}\right]$ can be obtained and its inverse matrix is:

$$
\tilde{\boldsymbol{L}}^{-1}=\left[\begin{array}{ccccccc}
0.1501 & 0.1499 & 0.1512 & 0.1397 & 0.1434 & 0.1517 & 0.1488 \\
0.3862 & -0.4688 & -0.0959 & 1.4260 & -1.1072 & 0.0533 & -0.1462 \\
0.9492 & 1.5076 & 0.6511 & -0.9364 & -1.2663 & 0.9070 & -1.9630 \\
0.7675 & -0.7889 & -1.8341 & 1.1638 & 2.6599 & 0.9046 & -2.6973 \\
3.2760 & -1.0776 & -2.5189 & -1.8519 & -0.7517 & 1.0198 & 1.7620 \\
5.2440 & -3.4082 & 4.9769 & -0.9315 & 1.5814 & -5.7765 & -1.6742 \\
1.9578 & 7.4260 & -4.8518 & 2.1439 & 0.3028 & -7.1767 & 0.4992
\end{array}\right]
$$

For the second step, the following weight vector in the SBM is obtained:

$v$ $=\left(-\frac{0.1470 \sqrt{\sigma_{x_{1} x_{1}}}}{x_{1}},-\frac{0.1464 \sqrt{\sigma_{x_{2} x_{2}}}}{x_{2}},-\frac{0.1491 \sqrt{\sigma_{x_{3} x_{3}}}}{x_{3}},-\frac{0.1282 \sqrt{\sigma_{x_{4} x_{4}}}}{x_{4}}, \frac{0.1347 \sqrt{\sigma_{y_{1} y_{1}}}}{y_{1}}, \frac{0.1502 \sqrt{\sigma_{y_{2} y_{2}}}}{y_{2}},-\frac{0.1444 \sqrt{\sigma_{b_{1} b_{1}}}}{b_{1}}\right)$

where $x_{1}, x_{2}, x_{3}, x_{4}, y_{1}, y_{2}$ and $b_{1}$ correspond to the number of FTE medical staff, nurses, other staff, capital charges, outpatient visits, inpatient discharges and readmissions.

According to prior discussions, solving equations (2.7) and (2.8) will give us the direction vector $\boldsymbol{g}$ in a DDF analysis that corresponds to the weight vector $\boldsymbol{v}$ found in the SBM. For example, the weight vector for the largest DHB Waitemata, in year 2017 , is

$v=(-0.0641,-0.0538,-0.0497,-0.0504,0.0399,0.0638,-0.0385)$,

and its equivalent direction vector is

$\boldsymbol{g}=(-0.6403,-1.9533,-4.7692,-5.8545,0.8679,0.0000,-7.4479)^{\prime}$.

Because of limited space, we do not list the vectors of $\boldsymbol{v}$ and $\boldsymbol{g}$ associated with all observations, they are available upon request to the authors. 


\section{Discussion of Efficiency Estimates}

Using the optimal weight vector $\boldsymbol{v}$ obtained above and solving the SBM programming problem (2.6), efficiency scores are computed based on this newly developed FAB-DDF model and the results are displayed in Table 3 and Figure $2 .{ }^{12}$

[Insert Table 3 and Figure 2 approximately here]

Wairarapa is the only DHB operating at full efficiency, while the other 19 DHBs have varying degrees of inefficiency. Over the entire sample period from 2011 to 2017, the average efficiency score is 91 percent. The rankings across different DHBs are quite robust in general when the results are compared with those obtained under conventional approaches, as displayed in Figure 2. More specifically, the results under the FAB-DDF model closely resembles those from (i) the SBM model in which $\boldsymbol{v}=\left(\frac{-1}{8} \frac{1}{x_{1}}, \cdots, \frac{-1}{8} \frac{1}{x_{4}}, \frac{1}{6} \frac{1}{y_{1}}, \frac{1}{6} \frac{1}{y_{2}}, \frac{-1}{6} \frac{1}{b_{1}}\right) ;$ (ii) the input orientated DEA with $\boldsymbol{g}=$ $(-\boldsymbol{x}, \mathbf{0}, \mathbf{0})^{\prime}$; (iii) the good-output orientated DEA with $\boldsymbol{g}=(\mathbf{0}, \boldsymbol{y}, \mathbf{0})^{\prime}$; (iv) the badoutput orientated DEA with $\boldsymbol{g}=(\mathbf{0}, \mathbf{0},-\boldsymbol{b})^{\prime}$; and (v) multi-dimensional orientated DDFs with $\boldsymbol{g}=(\boldsymbol{0}, \boldsymbol{y},-\boldsymbol{b})^{\prime}$ and $\boldsymbol{g}=(-\boldsymbol{x}, \boldsymbol{y},-\boldsymbol{b})^{\prime}$.

To investigate the main sources of inefficiency, we further decompose the overall efficiency score obtained under the FAB-DDF model into various dimensional efficiency components and the results are presented in Table 4.

\section{[Insert Table 4 approximately here]}

The main sources of inefficiency comes from the utilization of capital and other staff, as well as the control of bad output (readmissions). The average efficiencies associated with capital input $\left(e f f_{\text {cap }}\right)$ and readmission reduction $\left(e f f_{\text {readm }}\right)$ are 74.3 and 89.9 percent, respectively, which are much lower than the efficiencies for providing good outputs. The average efficiency score for inpatient-discharge is 99.1

\footnotetext{
12 efficiency $=1-$ inefficiency $=1-\overrightarrow{S B M}(\mathbf{z} ; \boldsymbol{v})$.
} 
percent, with the majority have been operating close to full efficiency. These results are expected given the focus on the volume of elective discharges without other controls in the National Health Targets against which performance of NZ DHBs are monitored.

To achieve full efficiency, the amount of FTE medical staff, nurse, and all other staff can be decreased by 8 percent, 3 percent and 10 percent, respectively on average. The greatest source of input inefficiency is capital, as measured by the capital charges, an average of 25.7 percent downscale has been estimated. With respect to output(s), the largest inefficiency is an average of 10 percent reduction in readmissions.

For each DHB, Table 4 provides an optimal direction to improve efficiency. For example, the Canterbury DHB should mostly focuse on capital utilization; the West Coast DHB could expand on the provision of good outputs (particularly inpatientdischarge) while keeping its capital charges in check, some might argue this is because of the small rural community West Coast DHB serves, i.e. caused by a shortage of demand instead of inefficient supply. The situation for the second smallest DHB (Tairawhiti) however is more complex, besides the extremely low capital efficiency score, it also needs to deal with excess in medical staff and inadequate provision of outpatient service. ${ }^{13}$ Full efficiency is achieved for inpatient discharges so that Tairawhiti would be judged to have better performance under the National Health Targets although other dimensions, as well as the overall efficiency score, are much worse compared to the West Coast.

\section{Shadow price analysis}

As shown in Figure 2, the conventional SBM of efficiency produces similar estimates

\footnotetext{
13 Since capital charges is used as the proxy for the flow of capital services, it is possible that inefficiency in capital input might reflect the underlying fact that some public hospitals are being over charged. Capital charges is supposed to capture the opportunity cost of capital used in public services, i.e. what will it cost if the same capital is leased to the private sector? Nonetheless, it is highly questionable whether or not public use of capital is equivalent to private use given the obvious externalities associated with public health services. It has been reported that the NZ hospitals are experiencing problems in replacing and upgrading critical infrastructures.
} 
as to the new FAB-DDF model. Meanwhile, the efficiency estimates obtained from conventional DDF analysis with the following direction vectors $\boldsymbol{g}=(-\boldsymbol{x}, \mathbf{0}, \mathbf{0})^{\prime}$, $(\mathbf{0}, \boldsymbol{y}, \mathbf{0})^{\prime},(\mathbf{0}, \boldsymbol{y},-\boldsymbol{b})^{\prime}$, and $(-\boldsymbol{x}, \boldsymbol{y},-\boldsymbol{b})^{\prime}$ are higher, and the estimates from $\boldsymbol{g}=$ $(\mathbf{0}, \mathbf{0}, \mathbf{b})^{\prime}$ are lower on average.

To illustrate the advantage of the new FAB-DDF approach, we compute the shadow price for medical staff. Under desirable theoretical properties, the salary paid to medical doctors should reflect its shadow price. Summary statistics of the average annual salary to medical staff are presented in Table 2. For a given level of efficiency and using the implicit differentiation rule:

$\frac{\partial z_{i}}{\partial z_{j}}=-\frac{\partial \overrightarrow{S B M}(\tilde{z} ; \boldsymbol{v}) / \partial \tilde{z}_{j}}{\partial \overrightarrow{S B M}(\tilde{z} ; \boldsymbol{v}) / \partial \tilde{z}_{i}} \sqrt{\sigma_{z_{i} z_{i}}} / \sqrt{\sigma_{z_{j} z_{j}}}$

the shadow price of $z_{j}$ with respect to $z_{i}$ is derived. By solving the FAB-DDF model, one can obtain $\partial \overrightarrow{S B M}(\tilde{\boldsymbol{z}} ; \boldsymbol{v}) / \partial \tilde{z}_{j}$ and $\partial \overrightarrow{S B M}(\tilde{\boldsymbol{z}} ; \boldsymbol{v}) / \partial \tilde{z}_{i}$. A vast amount of literature treats good-output as $z_{i}$. Hence, the shadow price of medical staff can be measured by:

$\frac{\text { dinpatient_discharge }}{\text { dmedical_staff_FTE }}$ or $\frac{\text { doutpatient_visit }}{\text { dmedical_staff_FTE }}$.

Because the units of measurement for outpatient-visit and inpatient-discharge are not in dollar terms, the nominal shadow price can be approximated as:

costs_per_discharge $\times \frac{\text { dinpatient_discharge }}{\text { dmedical_staff_FTE }}$

where the costs per discharge is obtained from the total expenditures on all personnel, outsourced clinical services and clinical supplies, the summary statistics are provided in Table 2. ${ }^{14}$ The correlation coefficients between the estimated shadow prices and the observed salary made to medical staff are displayed in Table 5. The shadow prices obtained under the new FAB-DDF approach always correlate more closely and

${ }^{14}$ Refer to Schmitt (2017) for the introduction and adjustment of the costs per discharge. 
significantly with the observed salary payment than those from other approaches.

[Insert Table 5 approximately here]

Furthermore, the efficiency decomposition displayed in Table 4 indicates that the major source of output inefficiency is readmission, the control of which has been left out by the National Health Targets. The shadow values, as explained in Färe et al. (2006), and the total shadow costs associated with readmission are given by:

readmission $\times$ costs_per_discharge $\times \frac{\text { dinpatient_discharge }}{\text { dreadmission }}$.

Since each DHB needs to reduce the number of readmission by $s_{b_{1}} \sqrt{\sigma_{b_{1} b_{1}}} / b_{1}$ in order to achieve full efficiency in the bad-output dimension, the total costs association with readmission reduction can be calculated as:

$s_{b_{1}} \sqrt{\sigma_{b_{1} b_{1}}} / b_{1} \times$ shadow costs_readmission.

The variations in shadow costs and reduction costs are presented in Figure 3, the top panel provides the average figure for each DHB during 2011-2017 and the bottom panel provides the national annual average. The largest DHB, Waitemata (WTM), has the highest readmission reduction costs (around \$105 million) and the second highest shadow costs (around \$291 million). Canterbury (CAN) has the highest shadow cost (around $\$ 330$ million), but it is efficient in minimizing readmissions. West Coast DHB (WTC) is the third one down the list facing high shadow costs associated with readmission. On average, the reduction costs of readmission is $\$ 10$ million over the last 7 years, implying substantial gain in health care efficiency from one of the missing component in the National Health Targets. The national average spikes in 2011 and 2016 (but falls in the years that follow) reassure this observation, which are the two years the issue of healthcare quality was brought up by the Heath Quality \& Safety Commission through the release of public reports.

[Insert Figure 3 approximately here] 


\section{Conclusions}

As DDF analysis becomes increasingly popular in estimating production technologies involving multiple-output and multiple-input, the issue of justifying the choice of appropriate directions becomes crucial for robust efficiency estimates. This study proposes a new approach, namely, factor-analysis-based DDF (FAB-DFF), which provides a non-radial endogenous optimal direction for efficiency improvement. It is built upon the fundamental equivalence embedded within DDF and SBM.

Compared to conventional DDF and SBM analysis, this new FAB-DDF model has a number of merits. First of all, as a non-radical measure it can help eliminate any potential bias introduced by radial measures (Fukuyama and Weber, 2009). Second, the directional choice is endogenous rather than exogenous. Pre-fixed exogenous directions do not consider the relative importance of distances (slacks) in each dimension. However, the FAB-DDF takes the advantages of the Mahalanobis distance and factor analysis through incorporating the correlation structure of the input-output dataset, i.e. the relative ease with which various input-output can be adjusted. Finally, unlike the endogenous directions put forward by Zofio et al. (2013), Atkinson and Tsionas (2016), Lee (2014), and Deng (2016), this new FAB-DDF model does not rely on additional price information. A step-by-step guide for application of this FABDDF model has been provided and a dataset containing all the public hospitals in NZ observed during 2011-2017 is utilized.

The efficiency scores computed using the new approach for NZ hospitals are compared with those obtained under conventional DDF and SBM analysis (with preassigned directions). The SBM provides similar efficiency estimates but the shadow price analysis shows that the estimates from the new FAB-DDF approach are more closely correlated with the observed salary paid to medical doctors. To achieve full efficiency, on average, the number of FTE medical staff, nurse, other staff, capital charges, and readmission within 28 days of discharge need to be reduced by $8.3 \%$, 
$3.1 \%, 10.1 \%, 25.7 \%$, and $10.1 \%$, respectively; and the number of price-weighted outpatient-visit and case-weighted inpatient-discharge can be increased by $7.3 \%$ and $0.9 \%$. The main source of inefficiency comes from the utilization of capital input, followed by readmission reduction. ${ }^{15}$ On average, the costs associated with reducing the number of readmission over the last 7 years is around $\$ 10$ million, implying that substantial gain in healthcare efficiency is possible if the mission components in the National Health Targets could be built into future policy initiatives governing the evaluation of hospital performance.

15 The final ranking of 20 District Health Boards in NZ is: Wairarapa (1st), Waikato (2nd), Bay of Plenty (3rd), Counties Manukau (4th), Auckland (5th), Lakes (6th), Canterbury (7th), Capital Coast (8th), Southern (9th), South Canterbury (10th), Nelson Marlborough (11th), Hawke's Bay (12th), West Coast (13th), Hutt Valley (14th), Taranaki (15th), MidCentral (16th), Northland (17th), Waitemata (18th), Whanganui (19th), Tairawhiti (20th) DHBs. 


\section{REFERENCES}

Agee, M. D. , S. E. Atkinson, and T. D. Crocker, 2012, "Child Maturation, Timeinvariant, and Time-varying Inputs: Their Interaction in the Production of Child Human Capital," Journal of Productivity Analysis, 38: 29-44.

Aletras, V. , N. Kontodimopoulos, A. Zagouldoudis, and D. Niakas, 2007, “The Shortterm Effect on Technical and Scale Efficiency of Establishing Regional Health Systems and General Management in Greek NHS Hospitals," Health Policy, 83(2-3): 236-245.

Ancarani, A. , C. Di Mauro, M. D. Giammanco, 2009, “The Impact of Managerial and Organizational Aspects on Hospital Wards' Efficiency: Evidence from a Case Study," European Journal of Operational Research, 194(1): 280-293.

Ashton, T. , 2005, "Recent Developments in the Funding and Organisation of the New Zealand Health System," Australia and New Zealand Health Policy, 2-9. http://doi.org/10.1186/1743-8462-2-9.

Ashton, T. , 2009, "New Zealand," in Cost Containment and Efficiency in National Health Systems, edited by J. Rapoport, P. Jacobs, and E. Jonsson. Weinheim, Germany: Wiley-VCH.

Atkinson, S. E. , and M. G. Tsionas, 2016, "Directional Distance Functions: Optimal Endogenous Directions," Journal of Econometrics, 190: 301-314.

Badau, F. , R. Färe, and M. Gopinath, 2016, "Global Resilience to Climate Change: Examining Global Economic and Environmental Performance Resulting from a Global Carbon Dioxide Market", Resource and Energy Economics, 45: 46-64.

Boivin, J, , and S. Ng, 2006, "Are More Data Always Better for Factor Analysis?" Journal of Econometrics, 132(1): 169-194.

Boyd, G. A. , G. Tolley, and J. Pang, 2002, "Plant Level Productivity, Efficiency, and Environmental Performance of the Container Glass Industry," Environmental and Resource Economics, 23: 29-43.

Brown, H. S. , 2003, "Managed Care and Technical Efficiency," Health Economics, 12(2): 149-158.

Chambers, R. G. , Y. Chung, and R. Färe, 1996, "Benefit and Distance Functions," Journal of Economic Theory, 70(2): 407-419.

Chambers, R. G. , Y. Chung, and R. Färe, 1998, "Profit, Directional Distance Functions, and Nerlovian Efficiency," Journal of Optimization of Theory and Applications, 98(2): 351-364.

Chambers, R. , R. Färe, S. Grosskopf, and M. Vardanyan, 2013, "Generalized Quadratic Revenue Functions," Journal of Econometrics, 173(1), 11-21.

Chang, H. , M. Cheng, and S. Das, 2004, "Hospital Ownership and Operating Efficiency: Evidence from Taiwan," European Journal of Operational Research, 159(2): 513-527.

Charnes, A., W. W. Cooper, and E. Rhodes, 1978, "Measuring the Efficiency of Decision Making Units," European Journal of Operational Research, 2: 429444. 
Chung, Y. , R. Färe, and S. Grosskopf, 1997, "Productivity and Undesirable Outputs: A Directional Distance Function Approach," Journal of Environmental Management, 51(3): 229-240.

Cumming, J. , J. McDonald, C. Barr, G. Martin, Z. Gerring, and J. Daubé, 2014, New Zealand Health System Review. World Health Organization.

Deng, Z. , 2016, "The Optimal Choice of Direction Vector in A Directional Distance Function," Systems Engineering - Theory \& Practice, 36(4): 934-944.

Eggleston, K. , "Multitasking and Mixed Systems for Provider Payment," Journal of Health Economics, 24: 211-223.

Färe, R. 1988, "Fundamentals of Production Theory", Springer Verlag, Berline, Germany.

Färe, R. , and S. Grosskopf, 2000, "Theory and Application of Directional Distance Functions," Journal of Productivity Analysis, 13: 93-103.

Färe, R. , S. Grosskopf, D. Noh, and W. L. Weber, 2005, "Characteristics of A Polluting Technology: Theory and Practice," Journal of Econometrics, 126: 469492.

Färe, R., S. Grosskopf, and W. L. Weber, 2006, "Shadow Prices and Pollution Costs in U.S. Agriculture," Ecological Economics, 56: 89-103.

Färe, R. , S. Grosskopf, C. A. Pasurka Jr, and W. L. Weber, 2012, "Substitutability among Undesirable Outputs", Applied Economics, 44(1): 39-47.

Färe, R. , S. Grosskopf, and G. Whittaker, 2013, "Directional Output Distance Functions: Endogenous Directions Based on Exogenous Normalization Constraints," Journal of Productivity Analysis, 40(3): 267-269

Farrell, M. J. , 1957, “The Measurement of Productive Efficiency," Journal of the Royal Statistical Society A, 120(3): 253-281.

Feng, G. , and A. Serletis, 2014, "Undesirable Outputs and A Primal Divisia Productivity Index Based on the Firectional Output Distance Function," Journal of Econometrics, 183: 135-146.

Foerster, A. T. , P.-D. G. Sarte, and M. W. Watson, 2011, "Sectoral versus Aggregate Shocks: A Structural Factor Analysis of Industrial Production," Journal of Political Economy, 119(1): 1-38.

Fraser, H. , and P. Nolan, 2017, "Understanding Health Sector Productivity," The New Zealand Productivity Commission Research Note 2017/08.

Friesner, D. , R. Mittelhammer, and R. Rosenman, 2013, "Inferring the Incidence of Industry Inefficiency from DEA Estimates," European Journal of Operational Research, 224(2): 414-424.

Fukuyama, H. , and W. L. Weber, 2009, “A Directional Slacks-based Measure of Technical Inefficiency,” Socio-Economic Planning Sciences, 43: 274-287.

Herr, A. , 2008, "Cost and Technical Efficiency of German Hospitals: Does Ownership Matter?" Health Economics, 17: 1057-1071.

Herr, A. , H. Schmitz, and B. Augurzky, 2011, "Profit Efficiency and Ownership of German Hospitals," Health Economics, 20: 660-674. 
Hudgins, L. B. , and D. Primont, 2007, "Derivative Properties of Directional Technology Distance Functions," in Aggregation, Efficiency, and Measurement, edited by R. Färe, S. Grosskopf, and D. Primont. Springer.

Johnson, R. , and D. Wichern, 2013, Applied Multivariate Statistical Analysis (Sixth Edition). London: Pearson Education Limited.

Krüger, J. J. , 2017, "Revisiting the World Technology Frontier: A Directional Distance Function Approach," Journal of Economic Growth, 22: 67-95.

Kumar, S. , 2006, "Environmentally Sensitive Productivity Growth: A Global Analysis Using Malmquist-Luenberger Index," Ecological Economics, 56: 280293.

Lee, Chia-Yen, 2014, "Meta-data Envelopment Analysis: Finding A Direction towards Marginal Profit Maximization," European Journal of Operational Research, 237(1): 207-216.

Lee, J. , J. Park, and T. Kim, 2002, "Estimation of the Shadow Prices of Pollutants with Production/Environment Inefficiency Taken into Account: A Nonparametric Directional Distance Function Approach," Journal of Environmental Management, 64: 365-375.

Luenberger, D. G. , 1992, “Benefit Functions and Duality," Journal of Mathematical Economics, 21: 461-486.

Luenberger, D. G. , 1994, “Optimality and the Theory of Value," Journal of Economic Theory, 63(2): 147-169.

Luenberger, D. G. , 1995, "Externalities and Benefits," Journal of Mathematical Economics, 24: 159-177.

Marcinko, D. E. , and H. R. Hetico, 2012, "Capital Formation Techniques for Hospitals," in Hospitals \& Health Care Organizations: Management Strategies, Operational Techniques, Tools, Templates, and Case Studies, edited by D. E. Marcinko, and H. R. Hetico. New York: Productivity Press.

Mays, N. , J. Marney, and E. King, 2013, "Fiscal Challenges and Changing Patterns of Need for Health and Long-Term Care in New Zealand," Policy Quarterly, 9(4): 35-46.

McFadden, D. , 1978, "Cost, Revenue, and Profit Function," in Production Economics: A Dual Approach to Theory and Applications, edited by M. Fuss, and D. McFadden. Amsterdam: North-Holland.

New Zealand Productivity Commission, 2017, Measuring and Improving State Sector Productivity: Draft Report. Wellington: New Zealand Productivity Commission.

Oxholm, A. S. , S. R. Kristensen, and M. Sutton, 2018, "Uncertainty about the Effortperformance Relationship in Threshold-based Payment Schemes," Journal of Health Economics, 62: 69-83.

Pang, R. , and Z. Deng, 2014, "Is Productivity of Service Sector Really Low?" Economic Research Journal, 10: 86-99.

Pang, R. , Z. Deng, and J. Hu, 2015, "Clean Energy Use and Total-factor Efficiencies: An International Comparison," Renewable and Sustainable Energy Reviews, 52: 1158-1171. 
Parkin, D. , and B. Hollingsworth, 1997, "Measuring Production Efficiency of Acute Hospitals in Scotland, 1991-94: Validity Issues in Data Envelopment Analysis," Applied Economics, 29(11): 1425-1433.

Petersen, N. C. , 2018, "Directional Distance Functions in DEA with Optimal Endogenous Directions," Operations Research, 66(4): 1068-1085.

Schmitt, M. , 2017, "Do Hospital Mergers Reduce Costs?" Journal of Health Economics, 52: 74-94.

Shephard, R. W. , 1970, Theory of Cost and Production Functions. Princeton: Princeton University Press.

Shephard, R. W. , and R. Färe, 1974, "The Law of Diminishing Return," Zeitschrift für Nationalökonomie (Journal of Economics), 34(1-2): 69-90.

Tone, K. A. , 2001, “A Slacks Based Measure of Efficiency in Data Envelopment Analysis," European Journal of Operational Research, 130: 498-509.

Vardanyan, M. , and D. Noh, 2006, “Approximating Pollution Abatement Costs via Alternative Specifications of A Multi-output Production Technology: A Case of the US Electric Utility Industry," Journal of Environmental Management, 80: 177-190.

Worthington, A. C. , 2004, "Frontier Efficiency Measurement in Health Care: A Review of Empirical Techniques and Selected Applications," Medical Care Research and Review, 61(2): 135-170.

Zelman, W. N. , M. J. McCue, A. R. Millikan, and N. D. Glick, 2009, Financial Management of Health Care Organizations: An Introduction to Fundamental Tools, Concepts, and Applications. UK: Blackwell Publishing.

Zofio, J. L. , J. T. Pastor, and J. Aparicio, 2013, “The Directional Profit Efficiency Measure: On Why Profit Inefficiency Is Either Technical or Allocative," Journal of Productivity Analysis, 40(3): 257-266. 
Table 1: Common directions in a DDF analysis

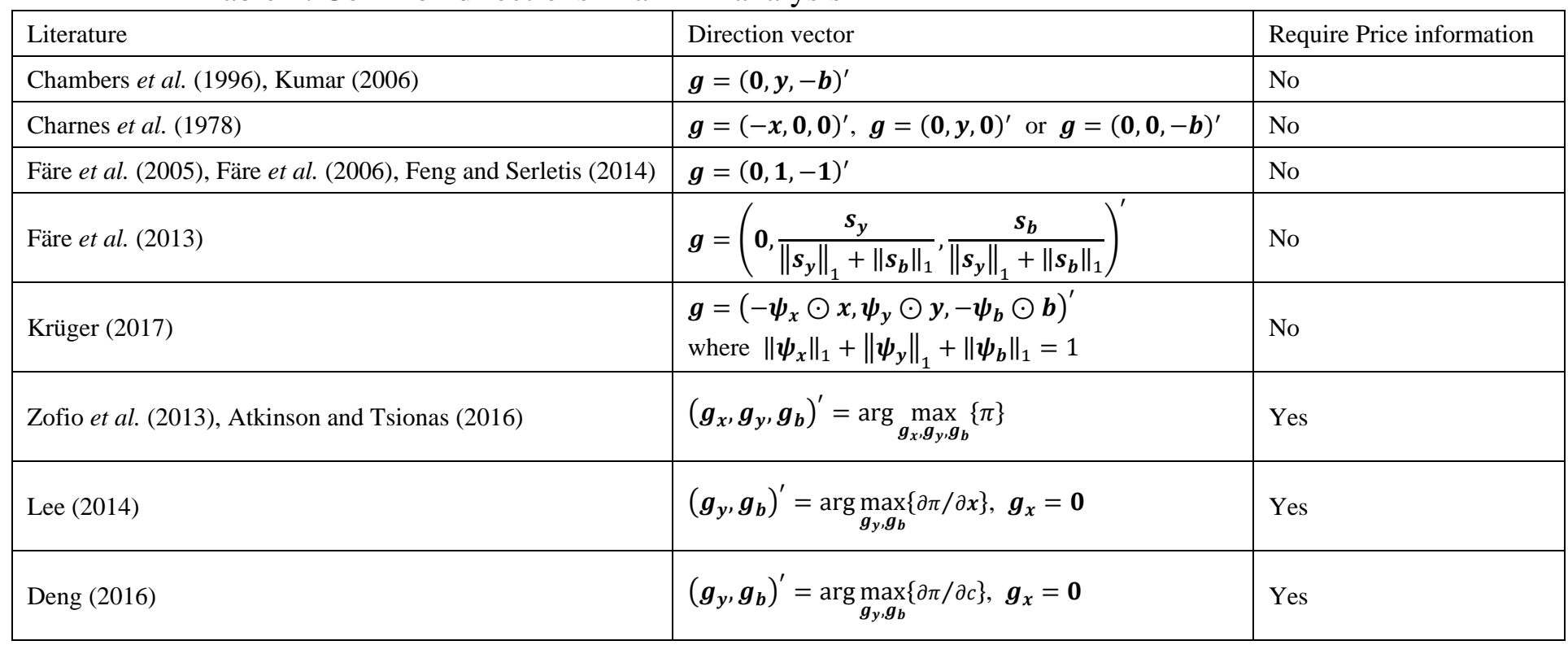

Source: authors' compliance.

$\odot$ denotes the Hadamard product of two vectors.

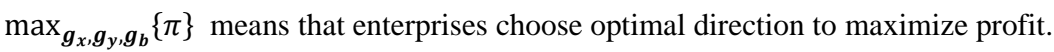

$\max _{\boldsymbol{g}_{\boldsymbol{y}}, \boldsymbol{g}_{\boldsymbol{b}}}\{\partial \pi / \partial \boldsymbol{x}\}$ means that enterprises choose optimal direction to maximize marginal profit of unit input.

$\max _{\boldsymbol{g}_{\boldsymbol{y}}, \boldsymbol{g}_{\boldsymbol{b}}}\{\partial \pi / \partial c\}$ means that enterprises choose optimal direction to maximize marginal profit of unit investment. 
Table 2: Summary of input-output variables during 2011-2017

\begin{tabular}{|c|c|c|c|c|c|c|c|c|c|c|}
\hline DHB & $\begin{array}{l}\text { Outpatient } \\
\text { Visits }\end{array}$ & $\begin{array}{l}\text { Inpatient } \\
\text { Discharges }\end{array}$ & Adverse Events & Readmissions & $\begin{array}{l}\text { Medical staff } \\
\text { (FTE) }\end{array}$ & $\begin{array}{l}\text { Nurses } \\
\text { (FTE) }\end{array}$ & $\begin{array}{l}\text { Other staff } \\
\text { (FTE) }\end{array}$ & $\begin{array}{l}\text { Capital Charges } \\
\text { (in \$1000) }\end{array}$ & $\begin{array}{l}\text { Salary to medical staff } \\
\text { (in } \$ 1000 \text { ) }\end{array}$ & $\begin{array}{l}\text { Total adjusted costs per } \\
\text { discharge (in } \$ 1000 \text { ) }\end{array}$ \\
\hline \multirow[t]{2}{*}{ Auckland } & 24,205 & 130,053 & 77 & 14,786 & 1,636 & 3,374 & 1,474 & 37,282 & 184.73 & 8.63 \\
\hline & $(1,764)$ & $(4,796)$ & (16) & (835) & (97) & (120) & (61) & $(3,818)$ & (13.09) & $(0.44)$ \\
\hline \multirow[t]{2}{*}{ Bay of Plenty } & 14,294 & 38,537 & 12 & 5,301 & 323 & 1,118 & 430 & 6,326 & 208.36 & 7.54 \\
\hline & $(920)$ & $(2,723)$ & (2) & $(461)$ & $(22)$ & $(42)$ & (26) & $(1,174)$ & $(6.94)$ & $(0.17)$ \\
\hline \multirow[t]{2}{*}{ Canterbury } & 25,387 & 92,574 & 54 & 9,544 & 950 & 3,542 & 1,258 & 13,809 & 194.85 & 8.31 \\
\hline & $(2,088)$ & $(4,281)$ & (10) & (947) & (51) & $(158)$ & (57) & $(4,122)$ & $(9.77)$ & $(0.32)$ \\
\hline \multirow[t]{2}{*}{ Capital Coast } & 17,655 & 65,528 & 21 & 7,150 & 795 & 2,059 & 749 & 8,364 & 165.84 & 8.26 \\
\hline & $(805)$ & $(3,240)$ & (4) & $(360)$ & (83) & (88) & (16) & $(1,311)$ & $(4.04)$ & $(0.23)$ \\
\hline \multirow[t]{2}{*}{ Counties Manukau } & 29,923 & 84,317 & 47 & 11,072 & 983 & 2,589 & 909 & 14,708 & 175.64 & 8.24 \\
\hline & $(1,265)$ & $(3,183)$ & (15) & (531) & (57) & (117) & (41) & $(2,702)$ & (11.25) & $(0.44)$ \\
\hline \multirow[t]{2}{*}{ Hawke's Bay } & 10,458 & 27,152 & 12 & 3,789 & 312 & 858 & 376 & 4,193 & 165.40 & 8.44 \\
\hline & $(656)$ & $(762)$ & (4) & (324) & $(22)$ & $(40)$ & $(10)$ & $(1,557)$ & $(9.38)$ & $(0.55)$ \\
\hline \multirow[t]{2}{*}{ Hutt Valley } & 10,585 & 23,130 & 8 & 3,207 & 251 & 729 & 354 & 6,207 & 192.87 & 8.52 \\
\hline & $(506)$ & $(1,131)$ & (2) & $(555)$ & (13) & (26) & (12) & $(1,196)$ & $(7.70)$ & $(0.19)$ \\
\hline \multirow[t]{2}{*}{ Lakes } & 6,986 & 17,440 & 10 & 3,200 & 170 & 485 & 208 & 3,410 & 202.81 & 7.65 \\
\hline & (324) & $(1,169)$ & (4) & (349) & (14) & (21) & $(10)$ & $(671)$ & $(7.31)$ & $(0.14)$ \\
\hline \multirow[t]{2}{*}{ MidCentral } & 11,606 & 28,133 & 19 & 3,845 & 308 & 960 & 422 & 8,529 & 196.40 & 9.02 \\
\hline & $(564)$ & $(791)$ & (2) & (205) & (20) & (29) & (8) & $(1,776)$ & $(5.21)$ & $(0.51)$ \\
\hline \multirow[t]{2}{*}{ Nelson Marlborough } & 9,746 & 21,402 & 13 & 2,638 & 191 & 644 & 454 & 6,104 & 238.26 & 9.60 \\
\hline & $(1,203)$ & (582) & (12) & (330) & (10) & (9) & (8) & $(1,085)$ & (11.98) & $(0.41)$ \\
\hline \multirow[t]{2}{*}{ Northland } & 10,243 & 27,483 & 13 & 4,277 & 272 & 973 & 421 & 7,926 & 210.38 & 9.23 \\
\hline & (974) & $(1,326)$ & (6) & (136) & (30) & (45) & (14) & $(1,788)$ & $(5.80)$ & $(0.56)$ \\
\hline
\end{tabular}


Table 2-continued: Summary of input-output variables during 2011-2017

\begin{tabular}{|c|c|c|c|c|c|c|c|c|c|c|}
\hline DHB & $\begin{array}{l}\text { Outpatient } \\
\text { Visits }\end{array}$ & $\begin{array}{l}\text { Inpatient } \\
\text { Discharges }\end{array}$ & Adverse Events & Readmissions & $\begin{array}{l}\text { Medical staff } \\
\text { (FTE) }\end{array}$ & $\begin{array}{l}\text { Nurses } \\
\text { (FTE) }\end{array}$ & $\begin{array}{l}\text { Other staff } \\
\text { (FTE) }\end{array}$ & $\begin{array}{l}\text { Capital Charges } \\
\text { (in } \$ 1000)\end{array}$ & $\begin{array}{l}\text { Salary to medical staff } \\
\text { (in } \$ 1000 \text { ) }\end{array}$ & $\begin{array}{l}\text { Total adjusted costs per } \\
\text { discharge (in \$1000) }\end{array}$ \\
\hline \multirow[t]{2}{*}{ South Canterbury } & 4,427 & 8,604 & 12 & 1,173 & 67 & 327 & 105 & 620 & 271.23 & 9.25 \\
\hline & $(276)$ & (200) & (6) & (103) & (6) & (6) & (4) & (117) & (15.23) & $(0.63)$ \\
\hline \multirow[t]{2}{*}{ Southern } & 19,508 & 52,084 & 41 & 6,151 & 519 & 1,593 & 632 & 8,607 & 222.01 & 8.37 \\
\hline & $(2,397)$ & $(1,761)$ & (12) & $(658)$ & (23) & (51) & (9) & $(1,679)$ & $(8.24)$ & $(0.39)$ \\
\hline \multirow[t]{2}{*}{ Tairawhiti } & 3,102 & 7,388 & 5 & 900 & 77 & 268 & 140 & 2,269 & 270.98 & 10.71 \\
\hline & (192) & (226) & (2) & $(48)$ & (4) & (14) & (3) & (493) & $(24.91)$ & $(0.60)$ \\
\hline \multirow[t]{2}{*}{ Taranaki } & 7,859 & 17,588 & 9 & 2,881 & 154 & 571 & 245 & 5,826 & 206.92 & 9.04 \\
\hline & (419) & (762) & (6) & (411) & (5) & $(22)$ & (8) & (733) & (16.93) & $(0.30)$ \\
\hline \multirow[t]{2}{*}{ Waikato } & 23,412 & 82,131 & 41 & 10,845 & 725 & 2,384 & 986 & 15,568 & 209.94 & 8.17 \\
\hline & $(1,455)$ & $(4,089)$ & (9) & $(1,448)$ & $(52)$ & (124) & (39) & $(1,800)$ & $(6.74)$ & $(0.31)$ \\
\hline \multirow[t]{2}{*}{ Wairarapa } & 3,559 & 6,174 & 5 & 890 & 49 & 212 & 87 & 487 & 234.02 & 8.56 \\
\hline & $(425)$ & (214) & (3) & (142) & (4) & (16) & (6) & (167) & (15.25) & $(0.45)$ \\
\hline \multirow[t]{2}{*}{ Waitemata } & 25,550 & 72,621 & 43 & 14,509 & 877 & 2,579 & 1,150 & 17,122 & 181.55 & 9.31 \\
\hline & $(4,154)$ & $(6,568)$ & (10) & $(1,885)$ & (74) & (194) & $(60)$ & $(4,546)$ & (7.87) & $(0.30)$ \\
\hline \multirow[t]{2}{*}{ West Coast } & 3,227 & 3,783 & 8 & 418 & 60 & 320 & 138 & 746 & 298.77 & 19.04 \\
\hline & (195) & (183) & (4) & (58) & (5) & (12) & (13) & (116) & (22.16) & $(0.72)$ \\
\hline \multirow[t]{2}{*}{ Whanganui } & 4,924 & 11,157 & 9 & 1,972 & 114 & 391 & 155 & 1,801 & 218.65 & 8.73 \\
\hline & $(364)$ & $(287)$ & (4) & (202) & (4) & (10) & (4) & $(372)$ & $(5.47)$ & $(0.52)$ \\
\hline
\end{tabular}


Table 3: Average efficiency estimates over 2011-2017

\begin{tabular}{|c|c|c|c|c|c|c|c|}
\hline \multirow{2}{*}{ DHB } & \multirow{2}{*}{ FAB-DDF } & \multirow{2}{*}{ SBM } & \multicolumn{5}{|c|}{ DDFs } \\
\hline & & & $(-x, \mathbf{0}, \mathbf{0})^{\prime}$ & $(\mathbf{0}, \boldsymbol{y}, \mathbf{0})^{\prime}$ & $(\mathbf{0}, \mathbf{0},-\boldsymbol{b})^{\prime}$ & $(0, y,-b)^{\prime}$ & $(-x, y,-b)^{\prime}$ \\
\hline \multirow[t]{2}{*}{ Auckland } & 0.980 & 0.979 & 1.000 & 1.000 & 0.985 & 1.000 & 1.000 \\
\hline & $(0.027)$ & $(0.027)$ & $(0.000)$ & $(0.000)$ & $(0.021)$ & $(0.000)$ & $(0.000)$ \\
\hline \multirow[t]{2}{*}{ Bay of Plenty } & 0.996 & 0.996 & 0.999 & 0.998 & 0.986 & 1.000 & 1.000 \\
\hline & $(0.007)$ & $(0.007)$ & $(0.003)$ & $(0.003)$ & $(0.034)$ & $(0.001)$ & $(0.000)$ \\
\hline \multirow[t]{2}{*}{ Canterbury } & 0.973 & 0.973 & 0.992 & 0.997 & 0.985 & 0.997 & 1.000 \\
\hline & $(0.046)$ & $(0.047)$ & $(0.020)$ & $(0.009)$ & $(0.029)$ & $(0.008)$ & $(0.000)$ \\
\hline \multirow[t]{2}{*}{ Capital Coast } & 0.965 & 0.962 & 0.983 & 0.982 & 0.960 & 0.986 & 0.994 \\
\hline & $(0.032)$ & $(0.034)$ & $(0.030)$ & $(0.024)$ & $(0.044)$ & $(0.018)$ & $(0.012)$ \\
\hline \multirow[t]{2}{*}{ Counties Manukau } & 0.984 & 0.985 & 1.000 & 0.993 & 0.972 & 0.997 & 1.000 \\
\hline & $(0.020)$ & $(0.020)$ & $(0.000)$ & $(0.009)$ & $(0.041)$ & $(0.006)$ & $(0.000)$ \\
\hline \multirow[t]{2}{*}{ Hawke's Bay } & 0.894 & 0.896 & 0.955 & 0.927 & 0.768 & 0.938 & 0.985 \\
\hline & $(0.054)$ & $(0.053)$ & $(0.025)$ & $(0.053)$ & $(0.117)$ & $(0.045)$ & $(0.015)$ \\
\hline \multirow[t]{2}{*}{ Hutt Valley } & 0.875 & 0.878 & 0.979 & 0.938 & 0.732 & 0.942 & 0.994 \\
\hline & $(0.058)$ & $(0.057)$ & $(0.032)$ & $(0.031)$ & $(0.122)$ & $(0.029)$ & $(0.016)$ \\
\hline \multirow[t]{2}{*}{ Lakes } & 0.975 & 0.974 & 0.998 & 0.998 & 0.894 & 0.998 & 1.000 \\
\hline & $(0.024)$ & $(0.026)$ & $(0.003)$ & $(0.004)$ & $(0.104)$ & $(0.004)$ & $(0.001)$ \\
\hline \multirow[t]{2}{*}{ MidCentral } & 0.831 & 0.832 & 0.922 & 0.833 & 0.714 & 0.870 & 0.969 \\
\hline & $(0.027)$ & $(0.028)$ & $(0.082)$ & $(0.030)$ & $(0.026)$ & $(0.019)$ & $(0.040)$ \\
\hline \multirow[t]{2}{*}{ Nelson Marlborough } & 0.899 & 0.905 & 0.996 & 0.972 & 0.877 & 0.975 & 1.000 \\
\hline & $(0.075)$ & $(0.071)$ & $(0.009)$ & $(0.024)$ & $(0.101)$ & $(0.022)$ & $(0.000)$ \\
\hline \multirow[t]{2}{*}{ Northland } & 0.810 & 0.806 & 0.893 & 0.814 & 0.636 & 0.858 & 0.965 \\
\hline & $(0.026)$ & $(0.029)$ & $(0.076)$ & $(0.061)$ & $(0.018)$ & $(0.055)$ & $(0.034)$ \\
\hline \multirow[t]{2}{*}{ South Canterbury } & 0.958 & 0.959 & 0.990 & 0.988 & 0.939 & 0.989 & 0.998 \\
\hline & $(0.053)$ & $(0.052)$ & $(0.018)$ & $(0.021)$ & $(0.085)$ & $(0.020)$ & $(0.005)$ \\
\hline \multirow[t]{2}{*}{ Southern } & 0.964 & 0.962 & 0.974 & 0.980 & 0.936 & 0.985 & 0.990 \\
\hline & $(0.037)$ & $(0.039)$ & $(0.027)$ & $(0.021)$ & $(0.063)$ & $(0.016)$ & $(0.010)$ \\
\hline \multirow[t]{2}{*}{ Tairawhiti } & 0.744 & 0.747 & 0.964 & 0.962 & 0.804 & 0.982 & 0.990 \\
\hline & $(0.018)$ & $(0.017)$ & $(0.054)$ & $(0.066)$ & $(0.025)$ & $(0.031)$ & $(0.018)$ \\
\hline \multirow[t]{2}{*}{ Taranaki } & 0.845 & 0.842 & 0.986 & 0.923 & 0.637 & 0.951 & 0.997 \\
\hline & $(0.016)$ & $(0.018)$ & $(0.024)$ & $(0.030)$ & $(0.044)$ & $(0.048)$ & $(0.008)$ \\
\hline \multirow[t]{2}{*}{ Waikato } & 0.997 & 0.997 & 1.000 & 1.000 & 1.000 & 1.000 & 1.000 \\
\hline & $(0.007)$ & $(0.008)$ & $(0.000)$ & $(0.000)$ & $(0.001)$ & $(0.000)$ & $(0.000)$ \\
\hline \multirow[t]{2}{*}{ Wairarapa } & 1.000 & 1.000 & 1.000 & 1.000 & 1.000 & 1.000 & 1.000 \\
\hline & $(0.000)$ & $(0.000)$ & $(0.000)$ & $(0.000)$ & $(0.000)$ & $(0.000)$ & $(0.000)$ \\
\hline \multirow[t]{2}{*}{ Waitemata } & 0.806 & 0.808 & 0.966 & 0.877 & 0.556 & 0.940 & 1.000 \\
\hline & $(0.028)$ & $(0.031)$ & $(0.066)$ & $(0.097)$ & $(0.058)$ & $(0.088)$ & $(0.000)$ \\
\hline \multirow[t]{2}{*}{ West Coast } & 0.888 & 0.892 & 1.000 & 0.994 & 0.909 & 0.998 & 1.000 \\
\hline & $(0.091)$ & $(0.087)$ & $(0.000)$ & $(0.011)$ & $(0.095)$ & $(0.006)$ & $(0.000)$ \\
\hline Whanganui & 0.805 & 0.806 & 0.875 & 0.851 & 0.581 & 0.882 & 0.946 \\
\hline & $(0.015)$ & $(0.016)$ & $(0.025)$ & $(0.030)$ & $(0.055)$ & $(0.057)$ & $(0.029)$ \\
\hline Total & 0.909 & 0.910 & 0.974 & 0.951 & 0.844 & 0.964 & 0.991 \\
\hline & $(0.087)$ & $(0.086)$ & $(0.049)$ & $(0.069)$ & $(0.160)$ & $(0.055)$ & $(0.020)$ \\
\hline
\end{tabular}

In the SBM model, weight vector is the one used by Fukuyama and Weber (2009). 
Table 4: Decomposition of average efficiency during 2011-2017

\begin{tabular}{|c|c|c|c|c|c|c|c|c|}
\hline DHB & eff & eff $f_{\text {med }}$ & $e f f_{\text {nur }}$ & eff $f_{\text {oth }}$ & $e f f_{\text {cap }}$ & eff $f_{\text {outp }}$ & $e f f_{\text {inp }}$ & eff $f_{\text {readm }}$ \\
\hline Auckland & 0.980 & 0.988 & 0.996 & 0.974 & 0.946 & 0.961 & 1.000 & 0.987 \\
\hline Bay of Plenty & 0.996 & 1.000 & 0.998 & 0.997 & 0.989 & 0.996 & 1.000 & 0.993 \\
\hline Canterbury & 0.973 & 0.989 & 0.990 & 0.987 & 0.872 & 0.958 & 1.000 & 1.000 \\
\hline Capital Coast & 0.965 & 0.950 & 0.997 & 0.987 & 0.908 & 0.897 & 1.000 & 1.000 \\
\hline Counties Manukau & 0.984 & 0.971 & 0.996 & 0.997 & 0.954 & 0.988 & 1.000 & 0.980 \\
\hline Hawke's Bay & 0.894 & 0.844 & 0.990 & 0.880 & 0.657 & 0.952 & 1.000 & 0.907 \\
\hline Hutt Valley & 0.875 & 0.842 & 1.000 & 0.841 & 0.606 & 0.992 & 0.998 & 0.820 \\
\hline Lakes & 0.975 & 0.952 & 1.000 & 0.999 & 0.978 & 0.977 & 1.000 & 0.918 \\
\hline MidCentral & 0.831 & 0.848 & 0.930 & 0.835 & 0.518 & 0.879 & 1.000 & 0.766 \\
\hline Nelson Marlborough & 0.899 & 0.951 & 1.000 & 0.716 & 0.666 & 0.976 & 1.000 & 0.967 \\
\hline Northland & 0.810 & 0.931 & 0.894 & 0.803 & 0.497 & 0.790 & 1.000 & 0.709 \\
\hline South Canterbury & 0.958 & 0.916 & 0.960 & 0.983 & 0.939 & 0.956 & 1.000 & 0.952 \\
\hline Southern & 0.964 & 0.996 & 1.000 & 0.993 & 0.806 & 0.932 & 1.000 & 0.996 \\
\hline Tairawhiti & 0.744 & 0.660 & 0.945 & 0.721 & 0.252 & 0.623 & 1.000 & 0.933 \\
\hline Taranaki & 0.845 & 0.955 & 0.992 & 0.867 & 0.386 & 0.946 & 1.000 & 0.713 \\
\hline Waikato & 0.997 & 1.000 & 1.000 & 1.000 & 1.000 & 0.982 & 1.000 & 1.000 \\
\hline Wairarapa & 1.000 & 1.000 & 1.000 & 1.000 & 1.000 & 1.000 & 1.000 & 1.000 \\
\hline Waitemata & 0.806 & 0.893 & 0.867 & 0.697 & 0.601 & 0.932 & 0.997 & 0.634 \\
\hline West Coast & 0.888 & 0.936 & 0.859 & 0.869 & 0.777 & 0.949 & 0.819 & 1.000 \\
\hline Whanganui & 0.805 & 0.720 & 0.975 & 0.832 & 0.514 & 0.849 & 1.000 & 0.707 \\
\hline Total & 0.909 & 0.917 & 0.969 & 0.899 & 0.743 & 0.927 & 0.991 & 0.899 \\
\hline
\end{tabular}

eff is the average efficiency for each DHB over 2011-2017, obtained under the FAB-DDF model.

eff $f_{\text {med }}=\overline{\left(1-s_{x_{1}} \sqrt{\sigma_{x_{1} x_{1}}} / x_{1}\right)}$ is the average efficiency for medical staff.

ef $f_{\text {nur }}=\overline{\left(1-s_{x_{2}} \sqrt{\sigma_{x_{2} x_{2}}} / x_{2}\right)}$ is the average efficiency for the nurse input.

eff $f_{\text {oth }}=\overline{\left(1-s_{x_{3}} \sqrt{\sigma_{x_{3} x_{3}}} / x_{3}\right)}$ is the average efficiency for all other staff.

ef $f_{\text {cap }}=\overline{\left(1-s_{x_{4}} \sqrt{\sigma_{x_{4} x_{4}}} / x_{4}\right)}$ is the average efficiency for capital input.

ef $f_{\text {outp }}=\overline{\left(1-s_{y_{1}} \sqrt{\sigma_{y_{1} y_{1}}} / y_{1}\right)}$ is the average efficiency for outpatient-visit.

ef $f_{\text {inp }}=\overline{\left(1-s_{y_{2}} \sqrt{\sigma_{y_{2} y_{2}}} / y_{2}\right)}$ is the average efficiency for inpatient-discharge.

ef $f_{\text {readm }}=\overline{\left(1-s_{b_{1}} \sqrt{\sigma_{b_{1} b_{1}}} / b_{1}\right)}$ is the average efficiency for readmissions.

eff $=0.1470 \cdot$ eff $_{\text {med }}+0.1464 \cdot$ eff $_{\text {nur }}+0.1491 \cdot$ eff $_{\text {oth }}+0.1282 \cdot$ eff $_{\text {cap }}+0.1347 \cdot$ eff $_{\text {outp }}+0.1502$.

eff $f_{\text {inp }}+0.1444 \cdot$ eff $f_{\text {readm }}$. 
Table 5: Correlation coefficients between observed salary of medical staff and estimated shadow prices

\begin{tabular}{llll}
\hline Measures of Shadow Price for Medical Doctors & FAB-DDF & $\begin{array}{l}\text { Conventional } \\
\text { SBM }\end{array}$ & $\begin{array}{l}\text { Conventional DDF } \\
\text { with } \boldsymbol{g}=(\mathbf{0}, \boldsymbol{y}, \mathbf{0})^{\prime}\end{array}$ \\
\hline $\begin{array}{l}\text { Dinpatient_discharge } \\
\text { dmedical_staff_FTE }\end{array}$ & $0.5279^{* * *}$ & $0.5127^{* * * *}$ & 0.0247 \\
costs_per_discharge $\times \frac{\text { dinpatient_discharge }}{\text { dmedical_staff_FTE }}$ & $(0.0000)$ & $(0.0000)$ & $(0.7764)$ \\
& $0.5635^{* * * *}$ & $0.5305^{* * *}$ & 0.0496 \\
\hline
\end{tabular}

The values in parentheses are the significance of Pearson's correlation test. 


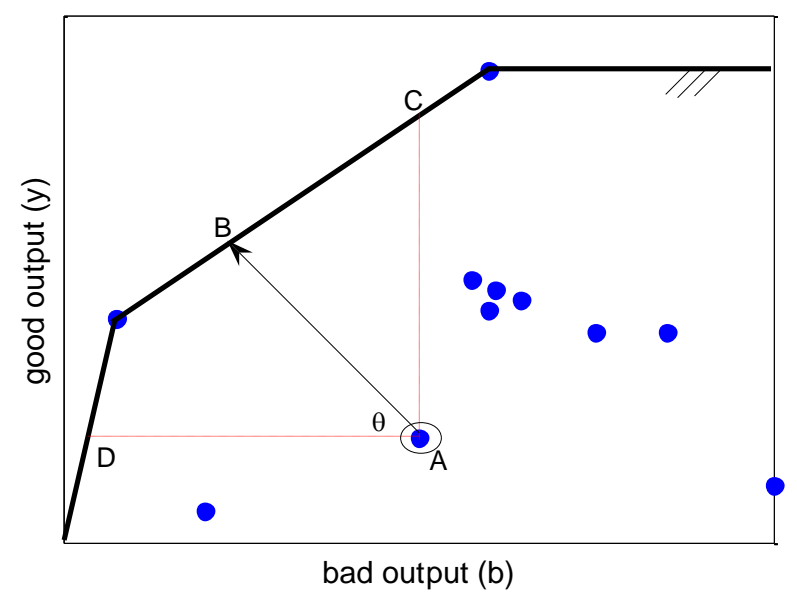

Figure 1 Direction selection in DDF and SBM

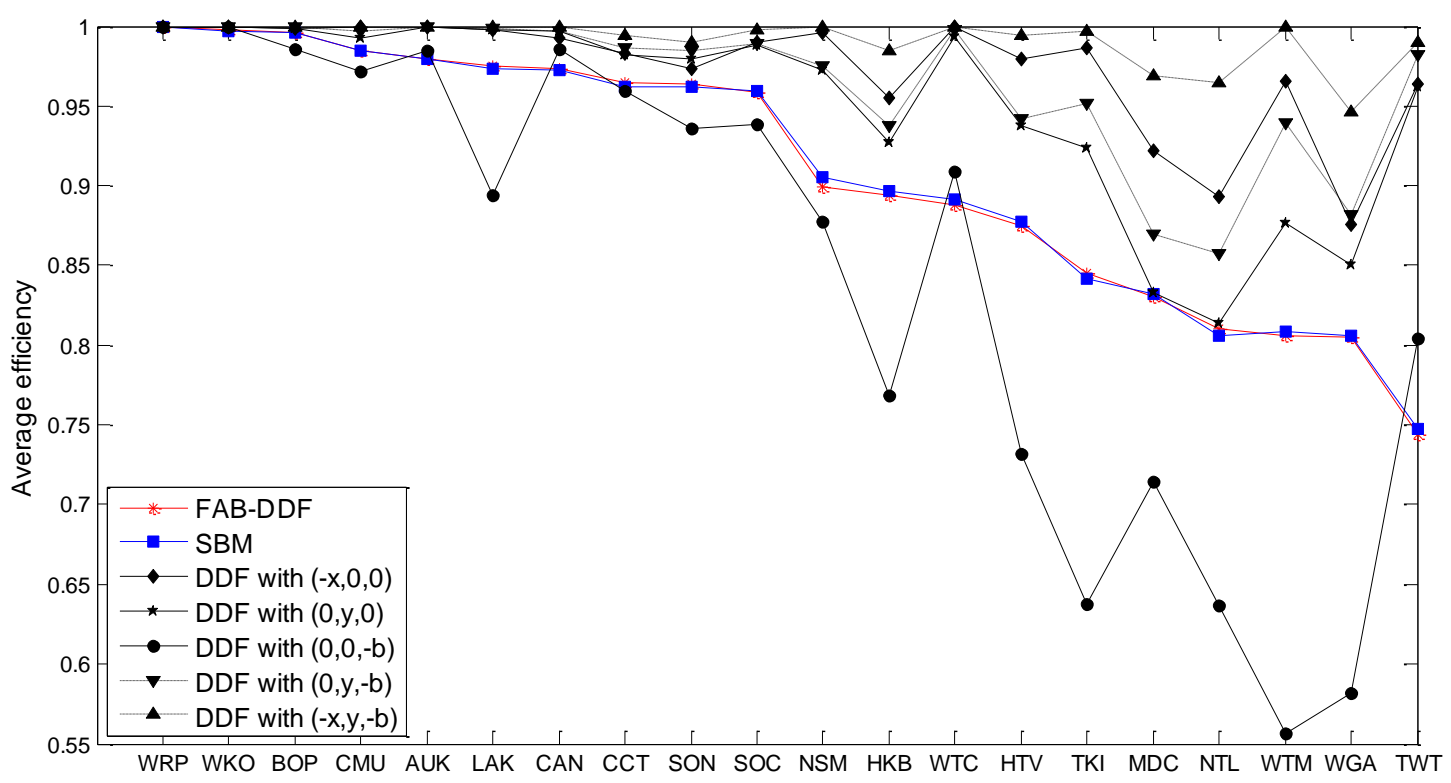

Figure 2 Average efficiency of NZ DHBs (2011-2017)

Wairarapa DHB: WRP; Waikato DHB: WKO; Bay of Plenty DHB: BOP; Counties Manukau DHB: CMU; Auckland DHB: AUK; Lakes DHB: LAK; Canterbury DHB: CAN; Capital Coast DHB: CCT; Southern DHB: SON; South Canterbury DHB: SOC; Nelson Marlborough DHB: NSM; Hawke's Bay DHB: HKB; West Coast DHB: WTC; Hutt Valley DHB: HTV; Taranaki DHB: TKI; MidCentral DHB: MDC; Northland DHB: NTL; Waitemata DHB: WTM; Whanganui DHB: WGA; Tairawhiti DHB: TWT. 

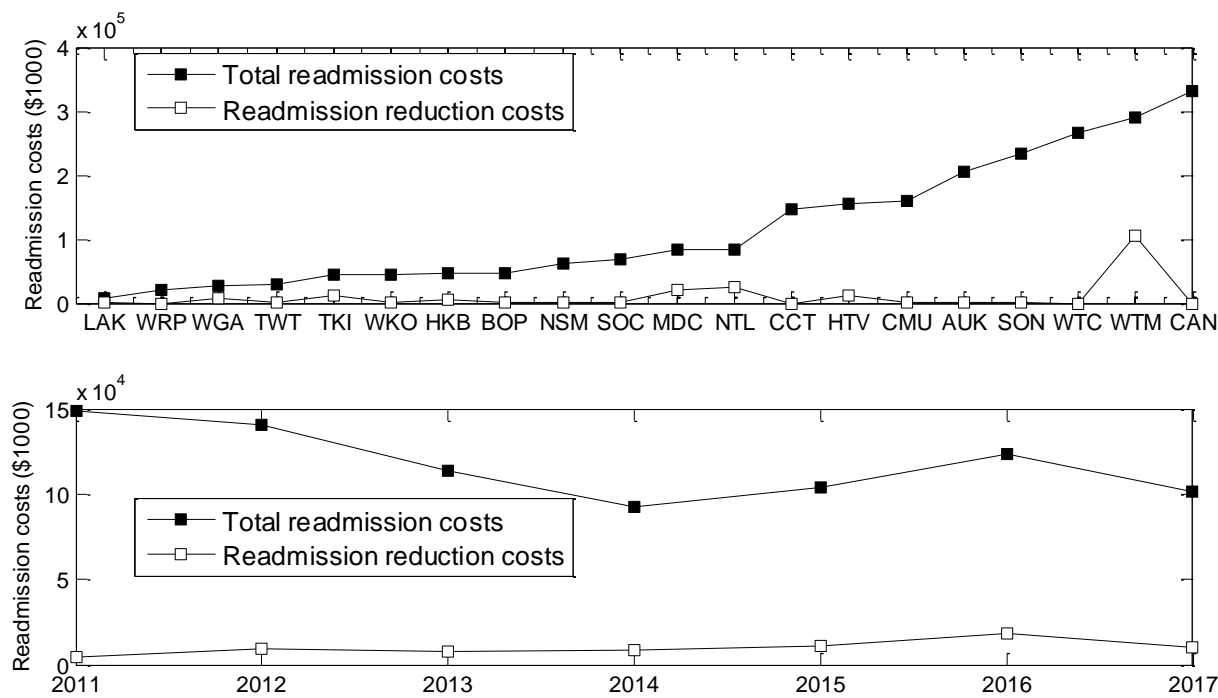

Figure 3 Readmission costs of NZ DHBs over 2011-2017

Calculated by the authors. Lakes DHB: LAK; Wairarapa DHB: WRP; Whanganui DHB: WGA; Tairawhiti DHB: TWT; Taranaki DHB: TKI; Waikato DHB: WKO; Hawke's Bay DHB: HKB; Bay of Plenty DHB: BOP; Nelson Marlborough DHB: NSM; South Canterbury DHB: SOC; MidCentral DHB: MDC; Northland DHB: NTL; Capital Coast DHB: CCT; Hutt Valley DHB: HTV; Counties Manukau DHB: CMU; Auckland DHB: AUK; Southern DHB: SON; West Coast DHB: WTC; Waitemata DHB: WTM;. Canterbury DHB: CAN. 


\section{Appendix 1: New Zealand DHBs}

\begin{tabular}{|c|c|c|}
\hline DHBs & Hospitals owned by each DHB & Population \\
\hline Auckland & Auckland City Hospital; and Starship Children's Hospital. & 460,000 \\
\hline Bay of Plenty & Tauranga Hospital; and Whakatane Hospital. & 220,000 \\
\hline Canterbury & $\begin{array}{l}\text { Christchurch Hospital; Christchurch Women's Hospital; } \\
\text { Burwood Hospital; The Princess Margaret Hospital; } \\
\text { Ashburton Hospital; and Hillmorton Hospital. }\end{array}$ & 501,425 \\
\hline Capital Coast & Wellington Hospital; and Kenepuru Hospital. & 300,000 \\
\hline Counties Manukau & $\begin{array}{l}\text { Middlemore Hospital; Manukau Super Clinic and Surgery } \\
\text { Centre. }\end{array}$ & 512,130 \\
\hline Hawke's Bay & Hawke's Bay Hospital. & 150,000 \\
\hline Hutt Valley & Hutt Hospital. & 140,000 \\
\hline Lakes & Rotorua Hospitals; and Taupo Hospital. & 108,000 \\
\hline MidCentral & Palmerston North Hospital; and Horowhenua Health Centre. & 166,000 \\
\hline Nelson Marlborough & Nelson Hospital and Wairau Hospital. & 134,500 \\
\hline Northland & $\begin{array}{l}\text { Whangarei Hospital; Bay of Islands Hospital; Dargaville } \\
\text { Hospital; and Kaitaia Hospital. }\end{array}$ & 154,700 \\
\hline South Canterbury & Timaru Hospital. & 55,626 \\
\hline Southern & $\begin{array}{l}\text { Dunedin Hospital; Wakari Hospital; Lake district Hospital; } \\
\text { and Southland Hospital. }\end{array}$ & 315,000 \\
\hline Tairawhiti & Gisborne Hopsital. & 46,000 \\
\hline Taranaki & Taranaki Base Hospital; and Hawera Hospital. & 110,000 \\
\hline Waikato & Waikato Hospital. & 360,000 \\
\hline Wairarapa & Wairarapa Hospital & 40,000 \\
\hline Waitemata & North Shore Hospital; and Waitakere Hospital & 560,000 \\
\hline West Coast & Grey base Hospital & 31,000 \\
\hline Whanganui & Whanganui Hospital & 60,120 \\
\hline
\end{tabular}




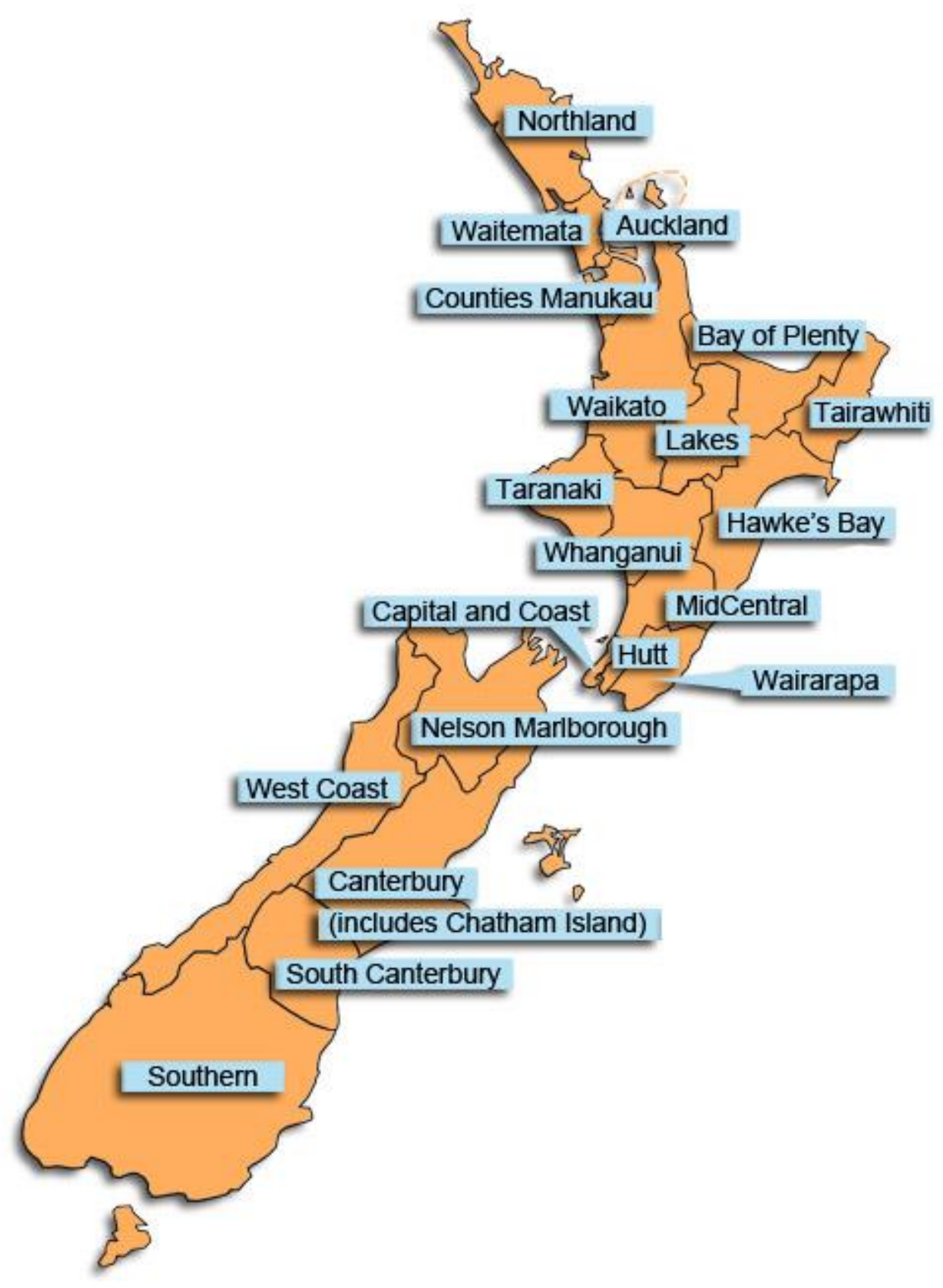




\section{Appendix 2: National Health Targets for 2017}

\begin{tabular}{|c|c|}
\hline $\begin{array}{l}\text { Shorter Stays } \\
\text { in Emergency } \\
\text { Departments }\end{array}$ & $\begin{array}{l}95 \% \text { of patients will be admitted, discharged, or transferred from an } \\
\text { emergency department within six hours. }\end{array}$ \\
\hline $\begin{array}{l}\text { Improved Access to } \\
\text { Elective Surgery }\end{array}$ & $\begin{array}{l}\text { The volume of elective surgery will be increased by an average of } 4000 \\
\text { discharges per year nationally. Each DHB is expected to meet the } \\
\text { agreed number of elective surgeries annually. }\end{array}$ \\
\hline $\begin{array}{l}\text { Faster Cancer } \\
\text { Treatment }\end{array}$ & $\begin{array}{l}85 \% \text { of patients receive their first cancer treatment (or other } \\
\text { management) within } 62 \text { days of being referred with a high suspicion of } \\
\text { cancer and a need to be seen within } 2 \text { weeks. }\end{array}$ \\
\hline $\begin{array}{l}\text { Increased } \\
\text { Immunisation }\end{array}$ & $\begin{array}{l}95 \% \text { of } 8 \text {-months-olds will have their primary course of immunisation } \\
\text { ( } 6 \text { weeks, } 3 \text { months and } 5 \text { months immunisation events) on time. }\end{array}$ \\
\hline $\begin{array}{l}\text { Better Help } \\
\text { for Smokers } \\
\text { to Quit }\end{array}$ & $\begin{array}{l}90 \% \text { of PHO enrolled patients who smoke have been offered help to } \\
\text { quit smoking by a health care practitioner in the last } 15 \text { months. }\end{array}$ \\
\hline $\begin{array}{l}\text { Raising } \\
\text { Healthy Kids }\end{array}$ & $\begin{array}{l}95 \% \text { of obese children identified in the B } 4 \text { School Check programme } \\
\text { will be offered a referral to a health professional for clinical assessment } \\
\text { and family-based nutrition, activity and lifestyle interventions by } \\
\text { December } 2017 \text {. }\end{array}$ \\
\hline
\end{tabular}

\section{Appendix 3: proof of equation (2.8)}

To make (2.5) equivalent to (2.6), the objective functions in (2.5) and (2.6) should be equal, therefore,

$$
(\boldsymbol{v} \boldsymbol{s})^{2}=\boldsymbol{s}^{\prime} \boldsymbol{s}\left(\boldsymbol{g}^{\prime} \boldsymbol{g}\right)^{-1}
$$

By condition (2.7) in main text, $\boldsymbol{s}=\tau \boldsymbol{g}$, where $\tau$ is a constant, substituting this relationship into (A1), obtaining:

$$
\tau^{2}(\boldsymbol{v} \boldsymbol{g})^{2}=\tau^{2} \boldsymbol{g}^{\prime} \boldsymbol{g}\left(\boldsymbol{g}^{\prime} \boldsymbol{g}\right)^{-1}
$$

Simplifying this equation, we obtain $\boldsymbol{v g}=1$. 


\section{Appendix 4: derivation of the variance contribution rate of factors}

The variance of variable $z_{i}(i=1, \cdots, N+M+B)$ is $\operatorname{Var}\left(z_{i}\right)$, the total variance of all the variables is $\operatorname{tr}(\boldsymbol{\Sigma})=\operatorname{Var}\left(z_{1}\right)+\operatorname{Var}\left(z_{2}\right)+\cdots+\operatorname{Var}\left(z_{N+M+B}\right)$, where $\operatorname{Var}\left(z_{i}\right)=l_{i 1}^{2}+l_{i 2}^{2}+\cdots+l_{i, N+M+B}^{2}$ because $\boldsymbol{\Sigma}=\boldsymbol{L} \boldsymbol{L}^{\prime}$ and $L \equiv$ $\left(l_{i j}\right)_{(N+M+B) \times(N+M+B)}$. Therefore, the contribution of the $j$ th common factor $F_{j}$ to $\operatorname{tr}(\Sigma)$ is $\sum_{i=1}^{N+M+B} l_{i j}^{2}$

According to $\boldsymbol{L}=\left[\sqrt{\lambda_{1}} \boldsymbol{e}_{1}, \cdots, \sqrt{\lambda_{N+M+B}} \boldsymbol{e}_{N+M+B}\right]$ mentioned in the main text,

$\sum_{i=1}^{N+M+B} l_{i j}^{2}=\left(\sqrt{\lambda_{j}} \boldsymbol{e}_{j}\right)^{\prime} \sqrt{\lambda_{j}} \boldsymbol{e}_{j}=\lambda_{j} \boldsymbol{e}_{j}^{\prime} \boldsymbol{e}_{j}$,

where $\boldsymbol{e}_{j}^{\prime} \boldsymbol{e}_{j}=1$, thereby $\sum_{i=1}^{N+M+B} l_{i j}^{2}=\lambda_{j}$.

Therefore, the variance contribution rate of factor $F_{j}$ to $\operatorname{tr}(\Sigma)$ equals $\frac{\lambda_{j}}{\operatorname{tr}(\boldsymbol{\Sigma})}$.

According to the properties of matrix trace, $\operatorname{tr}(\Sigma)=\sum_{i} \lambda_{i}$, so the variance

contribution rate of factor $F_{j}$ to $\operatorname{tr}(\Sigma)$ equals $\frac{\lambda_{j}}{\operatorname{tr}(\boldsymbol{\Sigma})}=\frac{\lambda_{j}}{\sum_{j} \lambda_{j}}$. After a standardization of variables by $\tilde{\mathbf{z}}=\left(\frac{z_{1}-\bar{z}_{1}}{\sqrt{\sigma_{11}}}, \cdots, \frac{z_{N+M+B}-\bar{z}_{N+M+B}}{\sqrt{\sigma_{N+M+B, N+M+B}}}\right)^{\prime}$, where $\bar{z}_{i}$ and $\sigma_{i i}$ are the sample mean and standard deviation of variable $z_{i}$, respectively, the total variance satisfies

$\operatorname{tr}(\widetilde{\boldsymbol{\Sigma}})=\operatorname{dim}(\widetilde{\boldsymbol{\Sigma}})=N+M+P$,

so $\frac{\widetilde{\lambda}_{j}}{\operatorname{tr}(\widetilde{\boldsymbol{\Sigma}})}=\frac{\widetilde{\lambda}_{j}}{N+M+B}$. 